\title{
Integrated Design and Control of Reactive Distillation Processes Using the Driving Force Approach
}

Iftakher, Ashfaq; Mansouri, Seyed Soheil; Nahid, Ahaduzzaman; Tula, Anjan K.; Choudhury, M. A. A. Shoukat; Lee, Jay Hyung; Gani, Rafiqul

\section{Published in:}

AIChE Journal

Link to article, DOI:

10.1002/aic. 17227

Publication date:

2021

Document Version

Peer reviewed version

Link back to DTU Orbit

Citation (APA):

Iftakher, A., Mansouri, S. S., Nahid, A., Tula, A. K., Choudhury, M. A. A. S., Lee, J. H., \& Gani, R. (2021). Integrated Design and Control of Reactive Distillation Processes Using the Driving Force Approach. AlChE Journal, 67(6), [e17227]. https://doi.org/10.1002/aic.17227

\section{General rights}

Copyright and moral rights for the publications made accessible in the public portal are retained by the authors and/or other copyright owners and it is a condition of accessing publications that users recognise and abide by the legal requirements associated with these rights.

- Users may download and print one copy of any publication from the public portal for the purpose of private study or research.

- You may not further distribute the material or use it for any profit-making activity or commercial gain

- You may freely distribute the URL identifying the publication in the public portal 


\title{
Integrated Design and Control of Reactive Distillation Processes Using the Driving Force
}

\section{Approach}

Ashfaq Iftakher ${ }^{1}$, Seyed Soheil Mansouri ${ }^{2}$, Ahaduzzaman Nahid ${ }^{1}$, Anjan K. Tula ${ }^{3}$, M. A. A. Shoukat Choudhury ${ }^{1}$, Jay Hyung Lee ${ }^{4}$, Rafiqul Gani ${ }^{4,5}$

${ }^{1}$ Department of Chemical Engineering, Bangladesh University of Engineering and Technology (BUET), Dhaka-1200, Bangladesh

${ }^{2}$ Department of Chemical and Biochemical Engineering, Technical University of Denmark, Søltofts Plads, Building 228A, 2800 Kgs. Lyngby, Denmark

${ }^{3}$ College of Control Science and Engineering, Zhejiang University, China

${ }^{4}$ Department of Chemical and Biomolecular Engineering, Korea Advanced Institute of Science and Technology (KAIST), South Korea

${ }^{5}$ PSE for SPEED Company, Skyttemosen 6, DK-3450 Allerod, Denmark

\begin{abstract}
Superior controllability of reactive distillation (RD) systems, designed at the maximum driving force (design-control solution) is demonstrated in this paper. Binary or multi-element single or double feed RD systems are considered. Reactive phase equilibrium data, needed for driving force analysis and design of the RD system, is generated through an in-house property prediction tool. Rigorous steady-state simulation is carried out in ASPEN plus in order to verify that the predefined design targets and dynamics are met. A multi-objective performance function is employed to evaluate the performance of the RD system in terms of energy consumption, sustainability metrics (total $\mathrm{CO}_{2}$ footprint), and control performance. Controllability of the designed system is evaluated using indices like the relative gain array (RGA) and Niederlinski This article has been accepted for publication and undergone full peer review but has not been through the copyediting, typesetting, pagination and proofreading process which may lead to differences between this version and the Version of Record. Please cite this article as doi: 10.1002/aic.17227@ 2021 American Institute of Chemical Engineers

Received: Sep 07, 2020;Revised: Dec 08, 2020;Accepted: Jan 10, 2021
\end{abstract}

This article is protected by copyright. All rights reserved. 
Index $\left(N_{I}\right)$, to evaluate the degree of loop interaction, as well as through dynamic simulations using proportional-integral (PI) controllers and model predictive controllers (MPC). The designcontrol of the RD systems corresponding to other alternative designs that do not take advantage of the maximum driving force is also investigated. The analysis shows that the RD designs at the maximum driving force exhibit enhanced controllability and lower carbon footprint than the alternative RD designs.

Keywords Reactive Distillation, Model Predictive Controller, Driving Force, Integrated DesignControl, Process Systems Engineering

\section{Introduction}

Reactive distillation (RD) takes advantage of the synergy created when combining heterogeneous/homogenous catalytic reactions or non-catalytic reactions and separation into a single unit ${ }^{1}$. RD improves the productivity and selectivity by primarily simultaneous removal of products from reactants as well as suppressing side reactions ${ }^{2}$, reduces capital cost as well as the need for solvents ${ }^{3}$, avoids/degrades azeotropes ${ }^{4}$, reduces energy usage by using the heat of exothermic reaction in-situ for the vaporization of the liquid, resulting in lower $\mathrm{CO}_{2}$ emission and less waste ${ }^{5}$, among others. These advantages not only attract industrial perspectives and applications $^{6}$ but also make $\mathrm{RD}$ a suitable intensified process to combat ever-increasing worldwide energy demand, which is expected to increase about 3.5 times (7 times increase in electricity demand) to sustain the ever-increasing population ${ }^{7}$. The potential of RD technology, however, has not yet been fully tapped, and there is still ongoing research to improve it further by other means, for example, ultrasound or microwave-assisted $\mathrm{RD}^{8}$, use of high-gravity fields (HiGee) $)^{9}$, and/or addressing issues such as operability and control ${ }^{10}$. There have been more than 150 successful industrial applications of $\mathrm{RD}$ technology ${ }^{11}$, for example, for selective 
hydrogenation of mixed hydrocarbons, selective desulfurization of mid catalytic naphtha, and isomerization of n-olefins to iso-olefins. In particular, RD systems have been reported for production of methyl acetate ${ }^{4}$, production of fuel additives or oxygenates (MTBE, ETBE, TAME) $^{6}$; toluene disproportionation to benzene and o-xylene ${ }^{12}$, hydrolysis of methyl acetate ${ }^{13}$, biodiesel production ${ }^{14}$, production of ethylene glycol ${ }^{15}$, production of silanes ${ }^{16}$, and many more.

Substantial amount of research has been done on the synthesis and/or design methods for RD systems over the years ${ }^{1}$. These include conceptual synthesis and design ${ }^{17,18}$, phenomena-based method approaches ${ }^{19}$, optimal design using deterministic and stochastic techniques ${ }^{20}$ and superstructure optimization ${ }^{21}$, graphical methods ${ }^{12}$, membrane-assisted reactive distillation processes $^{22}$, boundary value methods ${ }^{23-25}$, pinch based methods ${ }^{26}$, shortest stripping line method $^{27}$, to name a few.

Several control studies involving RD operations have been reported ${ }^{1}$. For the control of ethyl acetate production, Chien et al. ${ }^{28}$ employed a PI(D) controller to control tray temperature, while Vora and Daoutidis ${ }^{29}$ applied linear and nonlinear control strategies. For the control of ethylene glycol production, Heath et al. ${ }^{30}$ employed a PI controller while Kumar and Daoutidis ${ }^{31}$ considered output multiplicity and applied nonlinear inversion based controller. Wang et al. ${ }^{32}$ controlled tray temperature using a PI controller for diethyl carbonate synthesis. Al-Arfaj and Luyben $^{33}$ studied the use of a PI controller to control tray temperature and product purity for methyl acetate production. Medina-Herrera et al. ${ }^{34}$ worked on trichlorosilane decomposition and employed temperature control to ensure on-spec production of multiple products.

Applications of advanced control algorithms such as model predictive controller (MPC) are also reported for RD operation in the literature. Lee ${ }^{35}$ has reviewed the development and application of MPC. Some of the notable works include: controlling product purity in a TAME synthesis 
process $^{36}$; applying nonlinear MPC with a neural network model for controlling product purity of a methyl acetate RD system ${ }^{37}$. In the case of ethyl acetate production, Kawathekar and Riggs ${ }^{38}$ applied nonlinear MPC for controlling product purity; Venkateswarlu and Reddy ${ }^{39}$ applied nonlinear MPC based on stochastic optimization for controlling product purity, reboiler \& condenser holdups, and column pressure; Balasubramhanya and Doyle $\mathrm{e}^{40}$ applied nonlinear MPC to control tray temperature.

It is well-known that process design and process control, when considered independently, generally lead to conflicting objectives for the chemical processes, e.g., over design versus not robust design, or, infeasible versus economically suboptimal operating points ${ }^{41}$. Therefore, design and control issues are best addressed simultaneously (as in integrated process design and control) to obtain economically attractive, yet operationally feasible, and flexible processes. One of the convenient features of the simultaneous approach is the possibility to identify and eliminate potentially promising design alternatives that may have controllability problems due to a loss of degree of freedom, which shrinks the controllability region ${ }^{42}$. Various aspects of the simultaneous approach have been studied ${ }^{43-45}$. To name a few, simultaneous design and control of acidic acid production employing a PI(D) controller has been reported by Georgiadis et al. ${ }^{46}$ and Pistikopoulos and Sakizlis ${ }^{47}$. For ETBE production, Sneesby et al..$^{48}$ explored the interactions between design and control, while Bernal et al. ${ }^{49}$ considered phenomena such as column hydrodynamics and pressure drop across the column together with a rigorous dynamic model for simultaneous design and control. Chung et al. ${ }^{50}$ studied the design and control of a reactive distillation process for esterification of levulinic acid and n-butanol. However, work on integrated design-control using MPC has scarcely been reported. Francisco et al. ${ }^{51}$ reported a methodology for the simultaneous design of processes and linear MPCs, providing the plant 
dimensions, the control system parameters, and a steady-state working point simultaneously; Bahakim and Ricardez-sandoval ${ }^{52}$ proposed a methodology based on stochastic simultaneous design and MPC control of chemical processes under uncertainty. Mansouri et.al ${ }^{53}$ have shown that by simultaneously considering design and control issues through the driving force concept ${ }^{12,54}$, optimal design-control of reactive distillation units can be achieved. Here the driving force is defined as the difference in composition of a specific element between two coexisting phases and the plot of driving force versus liquid phase composition of component in a non-azeotropic binary mixture has a well-defined maximum. The main takeaway from this work is that a distillation column, whose feasibility of operation depends on the driving force, when designed on the basis of the maximum available driving force, would consume the least energy and also would be the easiest to operate ${ }^{54,55}$. Recently, Lopez-Arenas et al. ${ }^{56}$ proved theoretically that an $\mathrm{RD}$ column designed for operation at the maximum available driving force indeed corresponds to the minimum energy requirement. This means that if the maximum driving force can apriori be identified, the corresponding minimum energy consumption and easy operation can be obtained without formulating and solving an optimization problem for the design and therefore control of an $\mathrm{RD}$ column.

In this work, the development and application of a versatile framework for systematic integration of the driving force concept for design with various control methods, such as PI(D) and MPC, are presented. The results reported by Mansouri et al. ${ }^{57}$ are confirmed and extended through this framework. The main novelties of this work are as follows: 1) the extended framework now covers additional design-control options so that new RD systems in terms of configuration as well as reaction systems can be more easily introduced; 2) reactions are now not limited to only the liquid phase; 3) application and evaluation of advanced controllers such as MPC is now 
possible; 4) the extended framework has been converted to a computer-aided toolbox that guides the user through the steps of the work-flow of the integrated design-control method, provides access to in-house and/or external tools needed at each step, and, transfers the data from one step to another.

The extended framework allows for different configurations of the RD column and integrates the controller designs through a common set of variables that define both the design and control of the RD column operation. For example, product purity (a specification for process design also serves as a set-point value for the controller) is paired with reflux ratio (which is optimized in process design also serves as a reference value for the manipulated variable) at the maximum achievable driving force. For a reactive system, the toolbox based on the framework guides the user through the steps of the design and control algorithms and sets up the closed-loop simulation for verification. Application results for six RD column operations reported previously by others are presented together with the advantages of using the framework and toolbox.

This paper is organized as follows: First, an overview of the integrated design-control framework is presented. Next, the details of six case studies illustrating the application of the framework and toolbox are presented. Next, key results are discussed and the detailed design and closed-loop dynamics are presented for one case in the main manuscript, while the detailed results for the other case studies along with algorithms and mathematical derivations are given as supporting material. 2. Integrated Process Design-Control Framework

The framework for driving force based integrated design and control of RD processes is illustrated in Figure 1. This framework consists of three main steps: (1) Data collection and problem formulation; (2) Integrated design-control; (3) Verification. The integration of process design and control objectives is achieved in step 2 through operation at the maximum available 
driving force, which is achieved by identifying variables that can be assigned dual roles (a process design role and a controller design role) and whose values are determined from a driving force diagram of the reacting system. Table 1 lists a selection of these variables. The verification in step 3 is carried out through simulations in open-loop and closed-loop to evaluate the performance of the designed reactive distillation process with and without the controllers. This framework has been implemented in a new version of ProCACD ${ }^{58}$, an integrated software toolbox for process design and control, which also provides a link to needed property estimation tools as well as links to external tools (ASPEN PLUS, MATLAB). All case study results presented in this paper are obtained using this toolbox.

\section{[Figure 1]}

\section{[Table 1]}

\section{Step 1: Data collection and Problem formulation}

Step-1a: RD problem data and/or specification: Data/information on raw materials, products, catalysts, reaction conversions, and feed conditions (temperature, pressure, and composition) are collected, and design targets and product specifications are given. An objective function, which could be maximized (or minimized) from both the design and control perspectives, is defined. Note, however, with the driving force concept, a numerical optimization solver is not employed. Instead, the objective function serves to evaluate a multi-variable performance function at different design-control scenarios as the minimum in terms of energy consumption and ease of operation are related to the apriori located maximum driving force of the reacting system.

Step 1b: (Reactive system representation): In this step, the number and identity of elements needed 
to represent the reactive system are determined through the algorithm of Pérez-Cisneros et al. ${ }^{59}$. A revised version of this algorithm is given in section 2 of Supplementary Material as Algorithm-1s. The elements are transformed variables, proposed first by Ung and Doherty ${ }^{60}$ to reduce the dimensionality of the reactive system and thereby ease of visualization of the phase behavior. Later, Pérez-Cisneros et al. ${ }^{59}$ proposed algorithms for the simultaneous calculation of chemical and physical equilibrium by formulating the Gibbs energy minimization problem in terms of elements, where elements are atoms or groups of atoms and identified by the minimum set needed to represent the reacting system and to satisfy the atomic balance for all compounds (including inert compounds). Usually, it is the number of compounds (reactants and products) minus the number of reactions plus the number of inert compounds. If a binary element system is encountered, go to step-2; otherwise, go to Step 1c to identify the key pair of elements for the multi-element system.

Step 1c: (Identify the key elements): The equivalent binary elements, that is the light key and heavy key elements, are selected according to the rules of key element selection for a multielement system ${ }^{61}$, which are given in section 1 of Supplementary Material as Rules set-A.

\section{Step 2: Integrated design-control}

The objective of this step is to determine the RD process design ${ }^{12}$ (Step 2a) at the maximum driving force and the corresponding controller design.

Step $2 a$ (Design issues) - Step $2 a .1$ (Generate reactive vapor-liquid equilibrium data): The reactive vapor-liquid equilibrium (VLE) data is either obtained from experiments or computation of reactive bubble points and/or dew points, for which the algorithm of Daza et al., ${ }^{12}$, which is available through the new toolbox in ProCACD ${ }^{58}$, is employed. This implemented 
algorithm in the toolbox generates binary and equivalent binary element reactive phase diagrams and is included as Algorithm 2s in section 2 of Supplementary Material. Note that in this algorithm, the choice of discretization may affect the accuracy of the results. Since the calculation of the reactive VLE data is not computationally expensive, one can decrease the discretization interval (in absence of miscibility gaps) to obtain a smoother curve.

Step $2 a$ (Design issues) - Step 2a.2 (Reactive distillation design based on binary or equivalent binary elements): The objective of this step is to determine the RD column design (i.e., number of stages, reflux ratio, and feed location) based on binary or equivalent binary element at the maximum driving force. The steps required to perform this task are given in Algorithm 3s (section 2 of Supplementary material) for a single feed RD column; and Algorithm 1 (described in detail in section 2.1) for a double feed RD column. The last step of Algorithm 3s or Algorithm 1, involves steady-state simulation of the designed process to verify that the design objectives are satisfied.

The reactive driving-force based on the binary elements (or binary equivalent elements) is calculated using Equation 1 as described by Daza et al. ${ }^{12}$, or in the case of equivalent binary elements, light key equivalent element compositions are used to calculate the driving force.

$$
D F=W_{i}^{v}-W_{i}^{l}=\frac{W_{i}^{l} \alpha_{i j}}{1+W_{i}^{l}\left(\alpha_{i j}-1\right)}-W_{i}^{l}
$$

As part of Algorithm 3s (section 2 of Supplementary Material), the reactive McCabe-Thiele algorithm is given as a sub-algorithm, which is applied to calculate the minimum number of stages (corresponding to the maximum available driving force) to obtain the desired product specifications (targets) defined in step 1. The calculation is based on the well-known McCabe and Thiele method ${ }^{62}$ for non-reactive distillation design. Daza et al. ${ }^{12}$ extended this method to 
include reactive binary element distillation columns, which can also be used for equivalent binary element columns.

For a double feed RD column with feed flowrates $H$ and $K$, Algorithm 1 is applied to design the column at the maximum driving force. Note that this algorithm is adapted from the original McCabe-Thiele method ${ }^{62}$ for the design of distillation columns with two feeds.

Step $2 b$ (Optimal design-control issues): In this step, the control structure is selected with respect to two main criteria (sensitivity of controlled variables with respect to disturbances in the feed and sensitivity of manipulated variables to controlled variables) that are highlighted in Algorithm 4s (section 2 of Supplementary Material). The performance of the control structure is verified at the maximum driving force analytically using Algorithm 4s (section 2 of Supplementary Material). The application of this concept is analytically illustrated by Mansouri et al., ${ }^{53,57}$ where it is shown that the sensitivity of controlled variables with respect to feed disturbance is minimum, and the sensitivity of controlled variables with respect to manipulated variables is maximum for $\mathrm{RD}$ columns designed at the maximum available driving force. These two conditions ensure minimum control moves. Thus, the term 'optimal' in this work is used in a sense that the summation of control moves required is smaller than at other design (see results in section 4.2).

Step 3: Verification through simulation and analysis

The objective of this step is to verify the performance of the integrated design-control at the maximum driving force of the RD system through analysis of steady-state and dynamic simulation results. Figure 2 shows the process design - controller block diagram employed for verification steps. 


\section{[Figure 2]}

Step $3 a$ - Control structure verification: The applicability of the control structure obtained at the maximum binary element or equivalent binary element driving force, is verified by applying Algorithm 5s (section 2 of Supplementary Material). The control structure is verified by inspecting independently, the Relative Gain Array (RGA) values and the Niederlinski Index $\left(N_{I}\right)$ values. The stability of the RD systems is checked by the eigenvalue analysis of the open-loop and closed-loop dynamic models.

Step $3 b$ - Dynamic closed-loop analysis: The objective of this step is to evaluate the closedloop performance of the control structure identified and verified in Step $2 b$ and Step 3a, respectively, in the presence of disturbances by applying Algorithm 6s (section 2 of Supplementary Material). The disturbance is introduced through feed flow rate (and composition).

Step $3 c$ - Selection: In this step, the value of each term of the performance (objective) function (see Eq. 2) is calculated.

\subsection{Algorithm 1: Driving force based RD design for a two feed column}

The objective is to find the RD column design (number of stages, reflux ratio, feed location) with two feeds at the maximum driving force for the specified design targets. This algorithm is an adopted version, proposed earlier by Mansouri ${ }^{55}$.

Step (i): Retrieve vapor-liquid equilibrium element data (for the binary or equivalent binary system using Algorithm 2s - see section 2 of Supplementary material). 
Step (ii): Calculate the driving forces for the entire composition domain using Equation (1), then plot $|D F|$ versus $W_{i}^{l}$ based on the light key element (or the equivalent light key element).

Step (iii): Identify the area of operation of the driving force diagram (reactive zone information), i.e., feed compositions (feed one and two), distillate $\left(W^{D}\right)$ and bottom $\left(W^{B}\right)$ compositions based on the light key element (or the equivalent light key element) using design targets set in Step 1.

In the text above, $W_{k}$ and $W_{h}$ are the compositions of the feeds; $W_{g}$ is the composition of feed-g if the mixture with the two feeds are mixed such that it corresponds to the maximum driving force on the $x$-axis of the driving force diagram $\left(D_{x}\right)$. Note also, if $W_{h}>W_{k}$, then the $H$ feed is placed higher in the RD column. If the area of operation is not between 0 and 1 on the x-axis, then a re-scale of the $x$-axis between 0 - 1 is performed

Step (iv): Determine the reflux ratio and boil-up ratio (similar to Step (iv) of Algorithm 3s).

Step (v): Construct the PTXY diagram using the vapor-liquid equilibrium (binary or equivalent binary) element data from Algorithm 2s.

Step (vi): Draw the angle bi-section line ( $45^{\circ}$ line), and locate $W^{D}, W^{B}, W_{h}, W_{k}$, and $W_{g}$ on the $x$-axis of the PTXY diagram.

Step (vii): The enrichment line for the middle of the column is found by joining the points where enrichment lines for the rectifying and stripping sections intersect the lines $x=W_{h}$ and $x=W_{k}$. Note that the rectifying and striping lines from Step (iv) are exactly the same 
as in the case of a single feed (see Algorithm 3s), i.e., they start from the top and bottom product compositions.

Step (viii): Find the minimum number of reactive stages by drawing the steps for stages.

Step (ix): Perform a steady-state simulation. If simulation indicates that the specified product composition has not been reached, then add non-reactive stages one-at-a-time to the top and bottom of the reactive section until the desired purification of the products is achieved.

\section{Application Examples - Case Study Data}

The framework for integrated process design and control of single feed binary and multi-element systems, and double feed multi-element system has been tested through the following six case

studies 1) production of Methyl-tert-Butyl-Ether without the presence of inert, 2) production of Methyl-tert-Butyl-Ether in the presence of inert, 3) production of methyl acetate, 4) toluene disproportionation, 5) production of Ethyl-tert-Butyl Ether and 6) production of Tert-AmylMethyl-Ether. It is assumed that equilibrium is achieved as the chemical reaction taking place is fast. In this section data related to step 1 of the framework is given.

\subsection{Step 1: Data collection and problem formulation}

Step-1a: The key information of Step-1a for the six cases is listed in Table 2, and the data collection for case study 3 is described in detail. Detailed description for the other cases is given in section 3 of Supplementary Material. For the production of methyl-acetate via a reactive distillation column (case study 3), two feeds having same flowrates, but one containing methanol and the other acetic acid are considered. Also, reactive and non-reactive sections are considered. The design objective in this section is to obtain the RD column design operating at the maximum driving force to produce high purity methyl-acetate. The reaction between 
methanol $(\mathrm{MeOH})$ and acetic acid (HOAc) yields methyl acetate (MeAc) and water $\left(\mathrm{H}_{2} \mathrm{O}\right)$. The reaction takes place in the liquid phase over a catalyst ${ }^{61}$. It is exothermic with heat of reaction of $-5.42 \mathrm{~kJ} / \mathrm{mol}$ and is given as follows:

$$
\operatorname{MeOH}\left(\mathrm{CH}_{4} \mathrm{O}\right)+\mathrm{HOAc}\left(\mathrm{C}_{2} \mathrm{H}_{4} \mathrm{O}_{2}\right) \rightleftharpoons \operatorname{MeAc}\left(\mathrm{C}_{3} \mathrm{H}_{6} \mathrm{O}_{2}\right)+\text { Water }\left(\mathrm{H}_{2} \mathrm{O}\right)
$$

The design targets for all the case studies are given in Table 1s-6s (section 4 of Supplementary Material). For case study 3, the design target for the reactive section of the RD column is specified - data is obtained from Jantharasuk et al. ${ }^{61}$. In order to verify the integrated design and control, a multi-objective performance function involving a set of metrics to evaluate control performance is considered, as given below:

$f_{o b j}=$ minimize $J_{1}, J_{2}, J_{3}, J_{4}, J_{5}, J_{6}$

where, $J_{1}=$ energy consumption associated with the process, $J_{2}=$ integral absolute error $(I A E)$, $J_{3}=$ total variation of the manipulated variables, $J_{4}=$ relative gain array $(\mathrm{RGA}), J_{5}=$ Niederlinski Index $\left(N_{I}\right)$, and $J_{6}=$ total $\mathrm{CO}_{2}$ footprint per $\mathrm{kg}$ feed.

Note that this is a multi-objective performance function, which takes into account both design objectives and control objectives. The values of steady-state metrics, $J_{1}$ and $J_{6}$, measure energyefficiency and environment friendliness of the process. $J_{2}$ and $J_{3}$ are controller performance metrics which are defined below:

$$
\begin{aligned}
& J_{2}=I A E=\int_{0}^{\infty}\left|y-y_{s p}\right| d t \\
& J_{3}=T V=\sum_{i=1}^{\infty}\left|u_{i+1}-u_{i}\right|
\end{aligned}
$$


The diagonal values of $J_{4}$ indicate the degree of interaction between control loops. $J_{5}$ indicates the system stability. Note that for a $2 \times 2$ system, $N_{I}$ and RGA are clearly related because $N_{I}=$ $1 /(1,1)_{R G A}$. Hence, the condition is that both have to be positive. Both metrics are included here to check the appropriateness of the control structure. The aim is not to get a weighted scalar value of this function but to evaluate each of the metrics separately and verify that $J_{1}, J_{2}, J_{3}$ and $J_{6}$ are the lowest, while $J_{4}$ and $J_{5}$ satisfy the controllability criteria for a design at the maximum driving force.

Step $1 b$ - Binary element reactive system representation: For case studies $1,4,5 \& 6$, the number of compounds is three and the number of reactions is one. So, the reactive system can be represented by two elements. The element matrix, choice of elements, and element reaction are given in Table 7s (section 5 of Supplementary Material).

Step $1 c$ - Identify the key elements: For case studies $2 \& 3$, the number of compounds is four and the number of reactions is one. So, these reactive systems can be represented by three elements. The element matrix, choice of elements, and element reaction for case studies 2 and 3 are given in Table 8s (section 5 of Supplementary Material) and Table 3, respectively. The key elements are chosen by following the Rules Set-A (section 1 of Supplementary Material). For both case studies, element C is selected as the non-key element. For case study 2, B and A are selected to be the light key (LK) and the heavy key (HK), respectively. For case study 3, element $\mathrm{A}$ is the light key element (LK) and element B is the heavy key element (HK).

\section{[Table 2]}

\section{[Table 3]}

\section{Applications - Case Study Results and Discussion}


In this section, the results from the application of the framework and the toolbox are given in detail for case study 3 together with some highlights related to the other case studies. Detailed results for the case studies are given in Supporting Material (see sections 6-8).

\subsection{Step 2: Integrated design-control at maximum driving force (IDC-MDF)}

Step $2 a$ - Design issues (Step 2a.1: Generate reactive vapor-liquid equilibrium data): The reactive VLE data for the six case studies are generated through Algorithm 2s by selecting the appropriate thermodynamic models. The data used for the six case studies are given in Table 9s (section 6 of Supplementary Material). A discretization interval of 0.05 is used in this work to calculate the VLE data. The calculated reactive bubble point for the entire composition space for all the six case studies are given in Figure 1s (section 6 of Supplementary Material). These represent the $T-W_{A}^{l}-W_{A}^{v}$ phase diagrams for binary element reactive systems or the $T-$ $W_{L K, e q}^{l}-W_{L K, e q}^{v}$ phase diagrams for multi-element reactive systems.

Step $2 a$ - Design issues (Step 2a.2 - Reactive distillation design based on binary or equivalent binary elements): The generated reactive VLE data in terms of compounds are converted to reactive driving force diagrams, as illustrated in Figure 3. Subsequently, the RD columns are designed at the maximum binary or equivalent binary element driving force. Note that, in the reactive driving force diagram (see Figure 3), point A denotes the location of the driving force for the column design at the maximum driving force, whereas point $\mathrm{B}$ denotes the location of the driving force for alternative design 1 (of which the design parameters are given in Table 8). The area of operation is identified on the $x$-axis of the reactive driving force diagram in terms of the light key element (for a binary element system) or equivalent light key element (for a multielement system). 


\section{[Figure 3]}

Operating area is defined by selecting light key or equivalent light key element distillate composition $\left(W_{A}^{D}\right.$ or $\left.W_{L K, e q}^{D}\right)$ and light key or equivalent light key element bottom composition $\left(W_{A}^{B}\right.$ or $W_{L K, e q}^{B}$ ) by following Algorithms 3s (section 2 of Supplementary Material) for single feed binary element systems. The points $D_{x}$ and $D_{y}$ corresponding to the maximum driving force are identified and consequently, the slopes of these operating lines are determined and correspond to the minimum reflux ratio $\left(R R_{\min }\right)$ and reboil ratio $\left(R B_{\min }\right)$. Therefore, the actual $R R$ and $R B$ values are obtained by multiplying $R R_{\min }$ and $R B_{\min }$ by 1.2, giving the new slopes of the operating lines. The number of stages $(\mathrm{N})$ is calculated for all case studies by applying the reactive McCabe-Thiele method. The results of the application of the reactive McCabe-Thiele method for all the case studies are given in Figure 2s-7s (section 7 in the Supplementary Material).

For case study 3 , since it is a two feed and multi-element system, the area of operation is identified on the $x$-axis of the reactive driving force diagram in terms of the equivalent light key element. The feed and design target compositions, which are converted to element basis are translated to equivalent element compositions. Note that the area of operation is rescaled between $0-1$ in the composition domain on the $x$-axis of the driving force diagram according to Algorithm 1. Note that, the composition of the feeds are $W_{h}$ and $W_{k}$; and the design targets are the distillate and bottom compositions $\left(W^{D}, W^{B}\right)$. The light key equivalent element is in pure state in one feed $\left(W_{k}=1\right)$ and does not exist in the other feed $\left(W_{h}=0\right)$. The feed (with methanol) that contains the light key element is introduced at the last reactive stage and the other feed (with acetic acid) that does not contain the light key element is introduced at the first 
reactive stage (counting from the top) to ensure countercurrent flow. Non-reactive stages are added to the top and bottom of the reactive zone, one at a time until the design targets are satisfied. The total number of stages includes the number of the reactive stages and non-reactive stages. Note that the reboiler and condenser are considered as non-reactive stages. Table 4 presents the RD column design parameters at the maximum driving force for the six case studies.

\section{[Table 4]}

Step 2b: Optimal design-control issues

The controlled variables (y) are the top and bottom compositions, and the manipulated variables (․ㅡ) are the reflux rate and the reboiler duty, which for all the case studies are listed in Table 10s (section 7 in the Supplementary Material). The values of $d D F / d W_{A}^{l}$ (for the binary elements) or $d D F_{L K, e q} / d W_{L K, e q}^{l}$ (for the multi-elements) are calculated and plotted versus $W_{A}^{l}$ (binary element)

or $W_{L K, e q}^{l}$ (multi-element) for the six case studies as shown in Figure 8 s (section 7 in the Supplementary Material). Note that the values for $d D F / d W_{A}^{l}$ (for the binary elements) or $d D F_{L K, e q} / d W_{L K, e q}^{l}$ (for the multi-elements) should be zero at the maximum driving force, since the reactive driving force diagrams are concave with a unique maximum. However, since our discretization interval was 0.05 , we have obtained a nonzero minimum value which can be improved by further decreasing the discretization interval. Nonetheless, a unique minimum is justified which, along with Algorithm 4s (section 2 in the Supplementary material), verifies that the design at the maximum driving force has the least sensitivity of the controlled variables to the disturbances; and the highest sensitivity of the controlled variables to the manipulated variables.

\subsection{Step 3: Verification through simulation and analysis}

This article is protected by copyright. All rights reserved. 
Step $3 a$ - Control structure verification: In order to verify the control structure, the linearized model of the process, i.e., the state-space model is obtained and the steady-state gain matrix is constructed for the $2 \times 2$ system. To verify the extent of loop interactions, Algorithm 5 s (section 2 in the Supplementary Material) is applied to generate the relative gain array (RGA), to calculate the Niederlinski index $\left(N_{I}\right)$, and to check the system stability, eigenvalue analysis of the RD system models both for open loop and closed loop system is carried out. The results are given in Table 5. It is found that the loop interactions are minimal since diagonal values are close to unity $\left(N_{I} \approx 1\right)$ and thereby the control schemes determined for the six case studies are checked.

Step $3 b$ - Dynamic open-loop and closed-loop analysis: In order to evaluate dynamic open-loop and closed-loop performances, Algorithm 6s (section 2 in Supplementary Material) is applied. The disturbance scenarios are presented in Table 6 which are introduced through the feed and expressed in terms of the percentage of feed flow rate. For all six case studies, at first, the openloop responses of the systems to the disturbances listed in Table 6 have been determined.

\section{[Table 5]}

\section{[Table 6]}

PI controller: The PI controllers are optimally tuned in ASPEN PLUS dynamics using IMC ruless $^{71}$. In addition to the controller pairings (see Table 10s), the distillate drum level and sump level are controlled by manipulating the distillate and bottom flow rate respectively. For the level controllers, proportional (P) type is employed, and they are included in the model equations to maintain the dynamic model's consistency and stability. Furthermore, a perfect pressure control is assumed, that is, pressure changes in the column are neglected. 
$\underline{M P C}$ : The $A, B$, and $C$ matrices for a standard continuous-time state-space model are obtained for the integrated design-control solution at the maximum driving force. $D$ matrix is zero. For a linear system with $p$ inputs, $q$ outputs, and $n$ state variables, $A^{n \times n}$ is the system matrix, $B^{n \times p}$ is the input matrix, $C^{q \times n}$ is the output matrix. Using the linear model of the process, an MPC controller is implemented to perform the closed-loop simulation on the designed RD column (plant). The plant inputs are: the condenser duty $-Q_{c}$, the reflux mass flow rate - $\mathrm{R}(\mathrm{kg} / \mathrm{hr})$, the reboiler duty $-Q_{R}$, the distillate mass flow rate $-\mathrm{D}(\mathrm{kg} / \mathrm{hr})$, the bottoms mass flow rate $-\mathrm{B}$ $(\mathrm{kg} / \mathrm{hr})$, and the feed molar flow rate $(\mathrm{kmol} / \mathrm{hr})$. The plant outputs are: the column pressure (stage 1) - P (atm), the mole fraction of the distillate of interest $-x^{D}$, the mole fraction of the bottoms of interest $-x^{B}$, the reflux drum liquid level - Rlev (m), and the sump liquid level - Slev (m). A linear MPC with MIMO control strategy is obtained. The weights on the controlled outputs are associated in such a way that the top and bottom compositions of interest received more relative importance to stay at their nominal set-points. The prediction horizon is set to 30 minutes (large enough to be insensitive to further increases in the prediction horizon), and the control horizon is set to 4 minutes (small enough to not be significantly computationally expensive).

Analysis of results: The open-loop and closed-loop performance for the integrated design-control solution are highlighted in Figures 4-6 for case study 3. For all other case studies, the open-loop and closed-loop performance are shown in Figure 9s-23s (section 8 in the Supplementary Material). The control structure performances for the PI controller and the MPC are highlighted for both disturbance 1 (+ $10 \%$ step change in methanol feed flow rate) and 2 (+ $10 \%$ step change in acetic acid feed flow rate). Figure 4 shows the open-loop responses of the controlled variables. Figure 5 shows the closed-loop responses of the controlled variables (product compositions at 
the top and bottom) as well as the manipulated variables (reflux and reboiler rates). Figure 6 compares the performances of the PI controller with MPC.

It can be noted from Figures 5-6 that the closed-loop responses with both PI controller and MPC corresponding to the IDC-MDF, are able to reject the disturbances and restore the controlled variables to their original set-points with relatively small efforts in the manipulated variables in both the top and bottom control loops. This is also expected since the RGA matrix has values close to unity in the diagonal and close to zero in the off-diagonal, implying minimal interactions between the control loops and facilitating efficient disturbance rejection.

\section{[Figure 4]}

\section{[Figure 5]}

\section{[Figure 6]}

Step 3c - Final selection: The values of the six terms of the multi-objective performance function (see Eq. 2) are calculated for all the case studies. The results for case study 3 are given in Table 7, while Table 11s (section 8 in Supplementary Material) lists the results for all the other case studies. Note that in Table 7, the performance function terms for case study 3 are calculated for disturbances 1 and 2 , which are $+10 \%$ step in the methanol feed flow rate and $+10 \%$ step in the acetic acid feed flow rate, respectively (see Table 6).

\subsection{Comparison with RD design not at the maximum driving force}

Further analysis of the RD column with IDC-MDF is made by comparing its performance with an alternative $\mathrm{RD}$ column design not corresponding to the maximum driving force. For the purpose of comparison, the number of stages is kept the same for all cases. Feed locations, 
reflux, and boil-up ratios are varied and the same control structure and controlled variables as the ones in the maximum driving force design are used for the consistency of comparison. Both PI and MPC controllers are used for closed-loop simulation for all the alternatives. Details of the alternative designs for all the cases are given in Table 8. The design targets for all case studies are satisfied. The RGA and $N_{I}$ values for the alternative designs are given in Table 12s (section 8.2 in the Supplementary Material). For all the case studies, the closed-loop performance under PI and MPC controllers for all the alternatives are evaluated for the disturbance scenario given in Table 6. The performance of the controllers is compared in terms of dynamic responses as well as the control actions for case study 3 at the alternative design. For other case studies, the results are shown in Figure 24s-33s (section 8.2 in the Supplementary Material). For case study 3, Figure 7 shows the transient responses of the controlled variables (product compositions at the top and bottom) as well as the manipulated variables (reflux and reboiler rates), while, Figure 8 compares the performances of the PI controller with MPC for the alternative RD design. It can be noted from Figures 7-8 that compared to Figures 5-6, the controllers are not able to efficiently restore all the controlled variables to their set-points. Furthermore, a relatively longer settling time is observed in the controlled variables. It was noted that for the alternative designs, the diagonal values of the RGA deviate further from unity, compared to IDC-MDF, requiring the controllers for the alternative designs to cope with a larger degree of loop interactions. Thus, it further verifies that moving away from the maximum driving force results in a more difficult control and/or operation of the RD column.

Finally, the multi-objective performance function values for both the IDC-MDF and the alternative design under both the PI and MPC controllers for case study 3 under both disturbance 
scenarios are given in Table 7. Table 13s and 14s (section 8.2 in the Supplementary material) list the performance function values for the other case studies.

\section{[Table 7]}

\section{[Table 8]}

\section{[Figure 7]}

\section{[Figure 8]}

\section{Conclusion}

The enhanced controllability of a design obtained through a decomposition based integrated design-control framework using the driving force concept has been highlighted. The framework has been applied to study six RD systems with different configurations. A multi-objective performance function that takes into account the steady-state sustainability metrics (total energy consumption, total carbon footprint) and dynamic control performance (total variations in manipulated variables, the integral absolute error in controlled variables) has been employed. The results show that the RD systems designed at the maximum driving force can be more easily controlled with less error through the PI controllers as well as the MPC controller. For each RD system, the control performance at this operating point is found to be better than other designs, which are not based on the maximum driving force. For a double feed, multi-element system (methyl-acetate production), it has also been demonstrated that the PI and MPC control structures can successfully reject the disturbances introduced through either of the two feeds for the integrated design-control solution. Therefore, it can be concluded that the design at the maximum driving force facilitates the control structure design and results in better controller performance, regardless of the choice of the controller (MPC or PI), compared to designs not 
corresponding to the maximum driving force. Current and future work will further extend the framework together with the toolbox with additional integration features and computer-aided tools to enable efficient, reliable, and systematic studies of a wider range of RD systems, including integrated design-control of dividing wall column systems with or without reactions. This way, the overall goal of establishing the RD systems as intensified process alternatives that can be designed to be both sustainable and controllable, would be achieved. Also, the goal is to extend this work to the optimization of design-control under uncertainty, considering also the weights for the different terms of the multi-objective performance function.

\section{References}

1 Tian Y, Demirel SE, Hasan MF, Pistikopoulos EN. An overview of process systems engineering approaches for process intensification: state of the art. Chem. Eng. Process. 2018;133: 160-210.

2 Lee HY, Jan CH, Chien IL, Huang HP.Feed-splitting operating strategy of a reactive distillation column for energy-saving production of butyl propionate. J. Taiwan Inst. Chem. Eng. 2010; 41(33): 403-413.

3 Babi DK, Lutze P, Woodley JM, Gani R. A process synthesis-intensification framework for the development of sustainable membrane-based operations. Chem. Eng. Process. Process Intensif. 2014; 28(86): 173-195.

4 Agreda VH, Partin LR. Reactive distillation process for the production of methyl acetate. US Patent 4435595 A, 1984.

5 Kiss AA. Novel Catalytic Reactive Distillation Processes for a Sustainable Chemical Industry, Top. Catal. 2019; 62:1132-1148.

6 Harmsen GJ. Reactive distillation: the front-runner of industrial process intensification: a full review of commercial applications, research, scale-up, design and operation. Chemical Engineering and Processing: Process Intensification. 2007;46(9):774-780.

7 Gani R, Bałdyga J, Biscans B, Brunazzi E, Charpentier JC, Drioli E, Feise H, Furlong A, Geem KMV, Hemptinne JC, Kate A, Kontogeorgis G, Manenti F, Marin G, Mansouri SS, Piccione PM, Povoa A, Rodrigo MA, Sarup B, Sorensen E, Udugama IA, Woodley JM. A multi-layered view of chemical and biochemical engineering. Chem. Eng. Res. \& Design.2020;155:133-145.

8 Werth K, Lutze P, Kiss AA, Stankiewicz AI, Stefanidis GD, Górak A. A systematic investigation of microwave-assisted reactive distillation: Influence of microwaves on separation and reaction. Chem. Eng. Process. 2015; 93: 87-97.

9 Cortes Garcia GE, van der Schaaf J, Kiss AA. A review on process intensification in HiGee distillation. J. Chem. Technol. Biot. 2017; 92: 1136-1156.

10 Tula AK, Eden MR, Gani R. Computer-aided process intensification: Challenges, trends and opportunities. AIChE J. 2020; 66(1).

11 Harmsen J. Process intensification in the petrochemicals industry: Drivers and hurdles for commercial implementation. Chemical Engineering and Processing: Process Intensification. 2010; 49(1):70-73.

12 Daza OS, Pérez-Cisneros ES, Bek-Pedersen E, Gani R. Graphical and stage-to-stage 
methods for reactive distillation column design. AIChE Journal. 2003; 49(11): 2822-2841.

13 Sander S, Flisch C, Geissler E, Schoenmakers H, Ryll O, Hasse H. Methyl Acetate Hydrolysis in a Reactive Divided Wall Column. Chem. Eng. Res. Des. 2007; 85: 149-154

14 Kiss AA, Sorin Bildea C. A review of biodiesel production by integrated reactive separation Technologies. J Chem Technol Biotechnol. 2012; 87: 861-879

15 An W, Lin Z, Chen J, Zhu J. Simulation and Analysis of a Reactive Distillation Column for Removal of Water from Ethanol - Water Mixtures. Ind. Eng. Chem. Res. 2014; 53: 6056-6064.

16 Medina-Herrera N, Tututi-Avila S, Jiménez-Gutiérrez A, Segovia-Hernández JG. Optimal design of Multi-Product Reactive Distillation for Silanes Production. Comput. Chem. Eng. 2017, 105, 132-141.

17 Doherty MF, Malone MF (2001) Conceptual design of distillation systems. McGraw-Hill, New York.

18 Almeida-Rivera CP, Swinkels PLJ, Grievink J. Designing reactive distillation processes: present and future. Comput Chem Eng. 2004; 28:1997-2020.

19 Lutze P, Babi DK, Woodley JM, Gani R. Phenomena Based Methodology for Process Synthesis Incorporating Process Intensification. Ind. Eng. Chem. Res. 2013; 52(22): 7127-7144.

20 Segovia-Hernández JG, Hernández S, Bonilla Petriciolet A. Reactive distillation: a review of optimal design using deterministic and stochastic techniques. Chem. Eng. Process. - Process Intensification. 2015;97:134-143.

21 Liñán DA, Bernal DE, Ricardez-Sandoval LA, Gómez JM. Optimal design of superstructures for placing units and streams with multiple and ordered available locations. Part II: Rigorous design of catalytic distillation columns. Comput Chem Eng. 2020; 139; 106845.

22 Holtbruegge J, Kuhlmann H, Lutze P. Process analysis and economic optimization of intensified process alternatives for simultaneous industrial scale production of dimethyl carbonate and propylene glycol. Chemical Engineering Research and Design. 2015; 95: 411-431.

23 Barbosa D, Doherty MF. Design and minimum-reflux calculations for single-feed multicomponent reactive distillation columns. Chemical Engineering Science. 1988b; 43(7): 1523-1537.

24 Barbosa D, Doherty MF. Design and minimum-reflux calculations for double-feed multicomponent reactive distillation columns. Chemical Engineering Science. 1988a; 43:23772389.

25 Dragomir RM, Jobson M. Conceptual design of single-feed kinetically controlled reactive distillation columns. Chemical Engineering Science. 2005; 60(18): 5049-5068.

26 Avami A, Marquardt W, Saboohi Y, Kraemer K. Shortcut design of reactive distillation columns. Chemical Engineering Science. 2012; 71:166-177.

27 Lucia A, Amale A, Taylor R. Distillation pinch points and more. Computers \& Chemical Engineering. 2008; 32(6): 1342-1364.

28 Chien IL, Chen K, Kuo CL. Overall control strategy of a coupled reactor/columns process for the production of ethyl acrylate. Journal of Process Control. 2008; 18(3): 215-231.

29 Vora N, Daoutidis P. Dynamics and Control of an Ethyl-Acetate Reactive Distillation Column. 2001. Ind. Eng, Chem. Res. 40; 833-849.

30 Heath JA, Kookos IK, Perkins JD. Process control structure selection based on economics. AIChE Journal. 2000; 46(10):1998-2016.

31 Kumar A, Daoutidis P. Dynamic Modeling, Analysis and Control of Ethylene Glycol Reactive Distillation Column. AIChE J. 1999; 45; 51-68.

32 Wang SJ, Cheng SH, Chiu PH, Huang K. Design and control of a thermally coupled reactive distillation process synthesizing diethyl carbonate. Industrial \& Engineering Chemistry Research. 2014; 53(14): 5982-5995.

33 Al-Arfaj MA, Luyben WL. Comparative control study of ideal and methyl acetate reactive distillation. Chemical Engineering Science. 2002; 57(24): 5039-5050.

34 Medina-Herrera N, Jiménez-Gutiérrez A, Ricardez-Sandoval LA, Tututi-Avila S. An approach 
for dynamic transitions in multiproduct reactive distillation columns. Chem. Eng. Proc. Process Intensification. 2020; 153; 107967.

35 Lee JH. Model predictive control: Review of the three decades of development. Int. J. Control Autom. Syst. 2011; 9(3): 415

36 Sharma N, Singh K. Model predictive control and neural network predictive control of TAME reactive distillation column. Chemical Engineering and Processing: Process Intensification. 2012; 59: 9-21.

37 Engell S, Fernholz G. Control of a reactive separation process. Chemical Engineering and Processing: Process Intensification. 2003; 42(3): 201-210.

38 Kawathekar R, Riggs JB. Nonlinear model predictive control of a reactive distillation column. Control Engineering Practice. 2007; 15(2): 231-239.

39 Venkateswarlu C, Reddy AD. Nonlinear model predictive control of reactive distillation based on stochastic optimization. Industrial \& Engineering Chemistry Research. 2008; 47(18): 69496960.

40 Balasubramhanya LS, Doyle III FJ. Nonlinear model-based control of a batch reactive distillation column. Journal of Process Control. 2000; 10(2): 209-218.

41 Rafiei M, Ricardez-Sandoval LA. New frontiers, challenges, and opportunities in integration of design and control for enterprise-wide sustainability. Comput. Chem. Eng. 2020; 132.

42 Alvarado-Morales M, Hamid MKA, Sin G, Gernaey KV, Woodley JM, Gani R. A model-based methodology for simultaneous design and control of a bioethanol production process. Comput. Chem. Eng. 2010; 34: 2043-2061.

43 Mehta S, Ricardez-sandoval LA. Integration of Design and Control of Dynamic Systems under Uncertainty: A New Back-Off Approach. Ind. Eng. Chem. Res. 2016; 55: 485-498.

44 Sharifzadeh M. Integration of process design and control: A review. Chem. Eng. Res. Des. 2013; 91: 2515-2549.

45 Yuan Z, Chen B, Sin G, Gani R. State-of-the-art and progress in the optimization-based simultaneous design and control for chemical processes. AIChE J. 2012;58: 1640-1659.

46 Georgiadis MC, Schenk M, Pistikopoulos EN, Gani R. The interactions of design control and operability in reactive distillation systems. Computers \& Chemical Engineering. 2002; 26(4): 735-746.

47 Pistikopoulos EN, Sakizlis V, Simultaneous design and control optimization under uncertainty in reaction/separation systems, Paper presented at the AIChE Symposium Series (2002).

48 Sneesby MG, Tade MO, Smith TN. Two-point control of a reactive distillation column for composition and conversion. J. Process Control. 1999; 9: 19-31.

49 Bernal DE, Carrillo-Diaz C, Gómez JM, Ricardez-Sandoval LA. Simultaneous Design and Control of Catalytic Distillation Columns Using Comprehensive Rigorous Dynamic Models. Ind. Eng. Chem. Res. 2018; 57; 2587-2608.

50 Chung YH, Peng TH, Lee HY, Chen CL, Chien IL. Design and Control of Reactive Distillation System for Esterification of Levulinic Acid and n-Butanol. Ind. Eng. Chem. Res. 2015; 54: 3341-3354.

51 Francisco M, Vega P, Álvarez H. Chemical Engineering Research and Design Robust Integrated Design of processes with terminal penalty. Chem. Eng. Res. Des. 2011; 89: 1011-1024.

52 Bahakim SS, Ricardez-sandoval LA. Simultaneous design and MPC-based control for dynamic systems under uncertainty: A stochastic approach. Comput. Chem. Eng. 2014; 63: 66-81.

53 Mansouri SS, Huusom JK, Gani R, Sales-Cruz M. Systematic integrated process design and control of binary element reactive distillation processes. AIChE J. 2016; 62: 3137-3154.

54 Gani R, Bek-Pedersen E. A Simple New Algorithm for Distillation Column Design. AIChE J. 2000; 46 (6); 1271-1274.

55 Mansouri SS. Integrated Process Design, Control and Analysis of Intensified Chemical Processes. Ph.D. Thesis. 2016. Technical University of Denmark, Lyngby, Denmark.

56 Lopez-Arenas T, Mansouri SS, Sales-Cruz M, Gani R, Pérez-Cisneros ES. A Gibbs energy- 
driving force method for the optimal design of non-reactive and reactive distillation columns. Computers \& Chemical Engineering. 2019; 128: 53-68.

57 Mansouri SS, Sales-Cruz M, Huusom JK, Gani R. Systematic integrated process design and control of reactive distillation processes involving multi-elements. Chem. Eng. Res. Des. 2016; 115: 348-364.

58 Tula AK, Wang J, Chen X, Mansouri SS, Gani R. ProCACD: A computer-aided versatile tool for process control. Computers \& Chemical Engineering. 2020; 136.

59 Pérez-Cisneros ES, Gani R, Michelsen ML. Reactive separation systems-I. Computation of physical and chemical equilibrium. Chem. Eng. Sci. 1997; 52:527-543.

60 Ung S, Doherty MF. Vapor-liquid phase equilibrium in systems with multiple chemical reactions. Chem. Eng. Sci. 1995; 50; 23-48.

61 Jantharasuk A, Gani R, Górak A, Assabumrungrat S. Methodology for design and analysis of reactive distillation involving multielement systems. Chem. Eng. Res. Des. 2011; 89:12951307.

62 McCabe WL, Thiele E. Graphical design of fractionating columns. Ind. Eng. Chem. 1925;17: 605-611.

63 Al-Jarallah AM, Lee AKK, Siddiqui MAB. Kinetics of methyl tertiary butyl ether synthesis catalyzed by sulphuric acid. Chem. Eng. J. 1988; 39: 169-174.

64 Lobão M, Alberton A, Melo S, Embiruçu M, Monteiro J, Pinto J. Kinetics of Toluene Disproportionation: Modeling and Experiments. Ind. Eng. Chem. Res. 2012; 51: 171-183.

65 Sneesby M, Tadé M, Datta R, Smith T. ETBE Synthesis via Reactive Distillation. 1. SteadyState Simulation and Design Aspects. Ind. Eng. Chem. Res. 1997; 36:1855-1869.

66 Umar M, Patel D, Saha B. Kinetic studies of liquid phase ethyl tert-butyl ether (ETBE) synthesis using macroporous and gelular ion exchange resin catalysts. Chem. Eng. Sci. 2009; 64: 4424-4432.

67 Françoisse O, Thyrion F. Kinetics and mechanism of ethyl tert-butyl ether liquid-phase synthesis. Chem. Eng. Proc.: Process Intensification. 1991; 30: 141-149.

68 Baur R, Taylor R, Krishna R. Bifurcation analysis for TAME synthesis in a reactive distillation column: Comparison of pseudo-homogeneous and heterogeneous reaction kinetics models. Chem. Eng. Process. 2003; 42: 211-221.

69 Al-Arfaj MA, Luyben WL. Plantwide control for TAME production using reactive distillation. AIChE J. 2004; 50: 1462-1473.

70 Luyben WL. 2013. Distillation Design and Control Using Aspen ${ }^{\mathrm{TM}}$ Simulation. John Wiley \& Sons, Ltd. ISBN 9781118510193, 9, 257-274.

71 Rivera DE, Morari M, Skogestad S. Internal model control: PID controller design. Ind. Eng. Chem. Res. 1986; 25: 252-265. 
Table 1: Common variables for design and control.

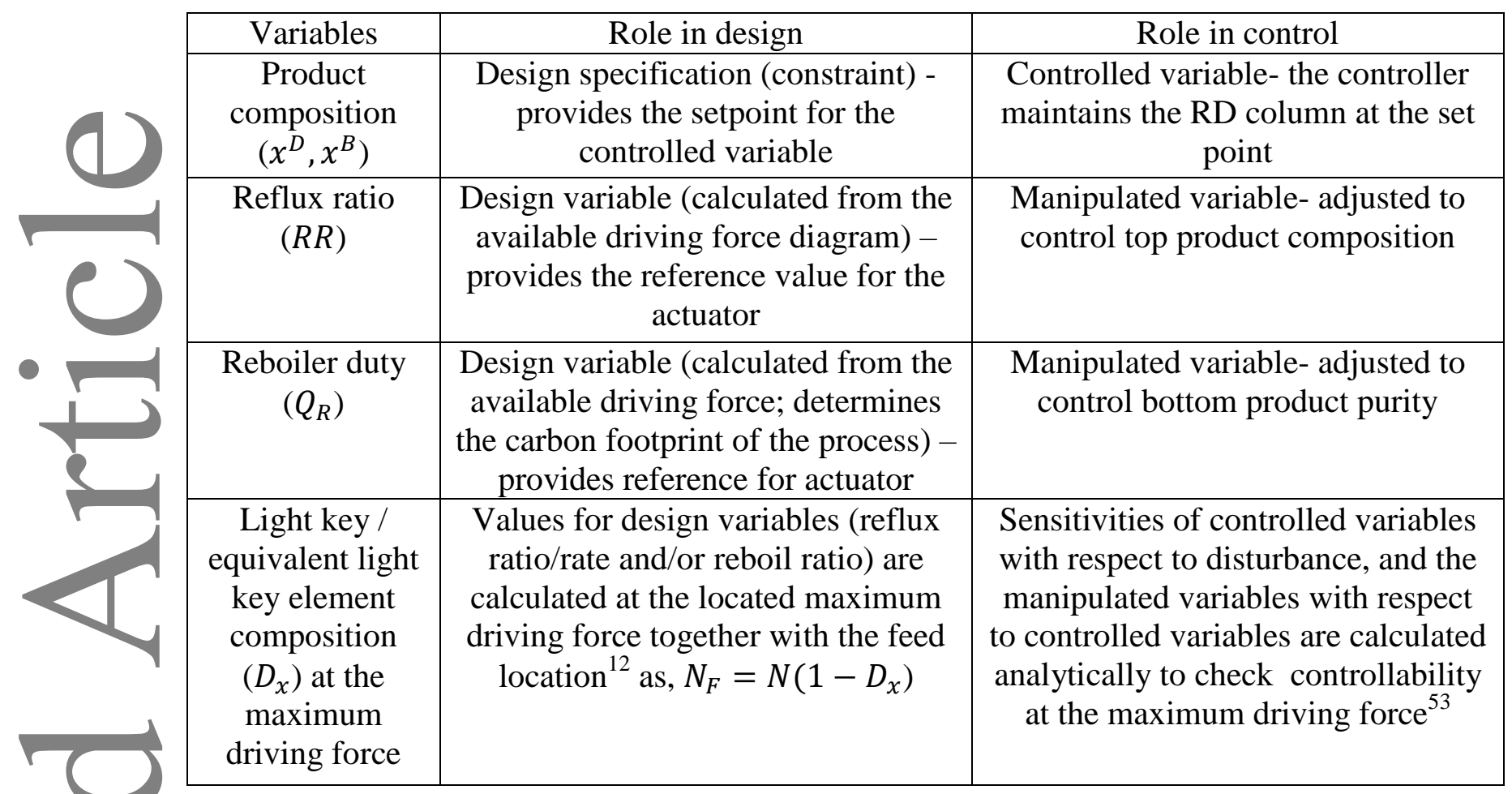

This article is protected by copyright. All rights reserved. 
Table 2: Key information for problem formulation (step 1).

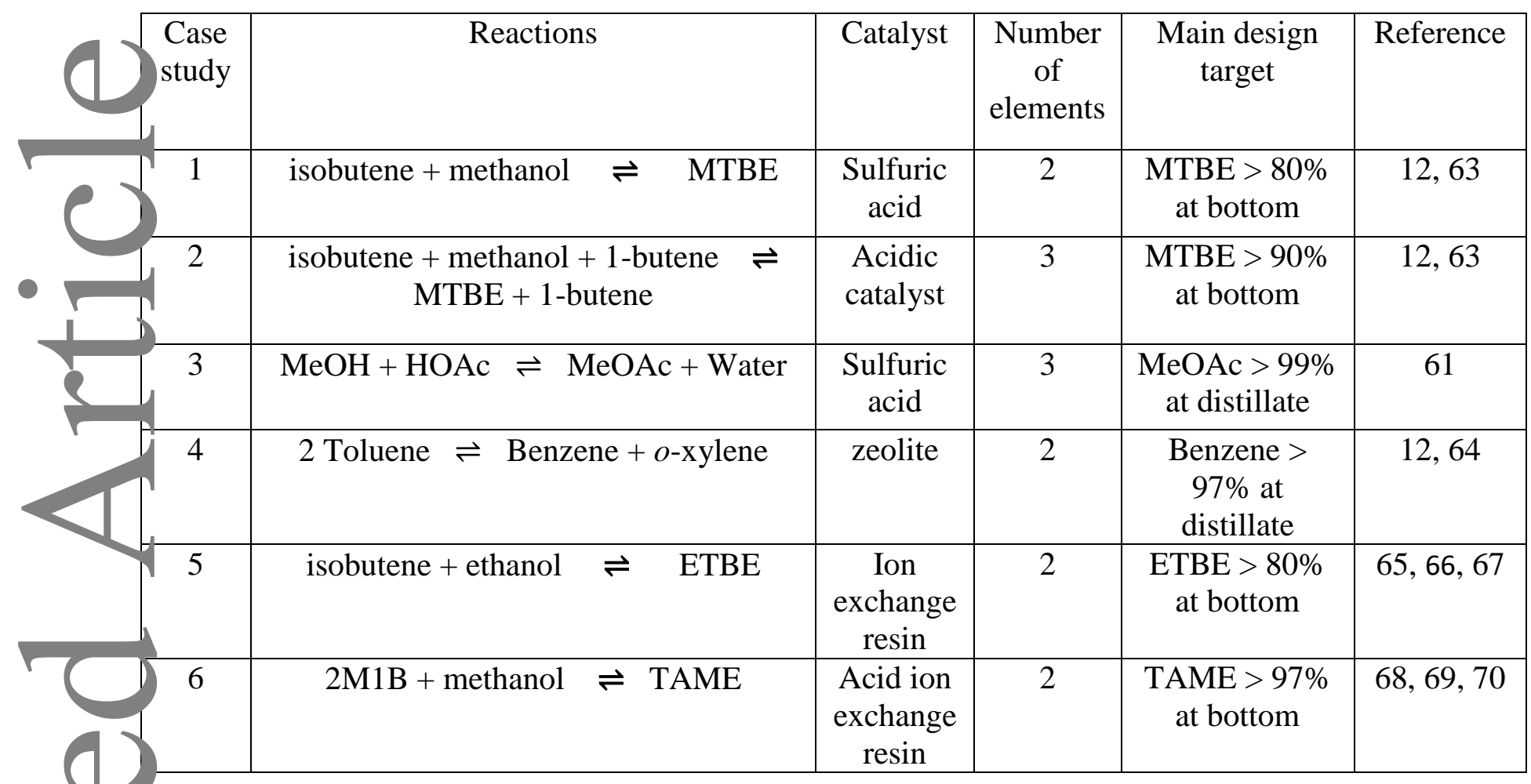

This article is protected by copyright. All rights reserved. 
Table 3: The element matrix and element reaction for the multi-element reactive systems.

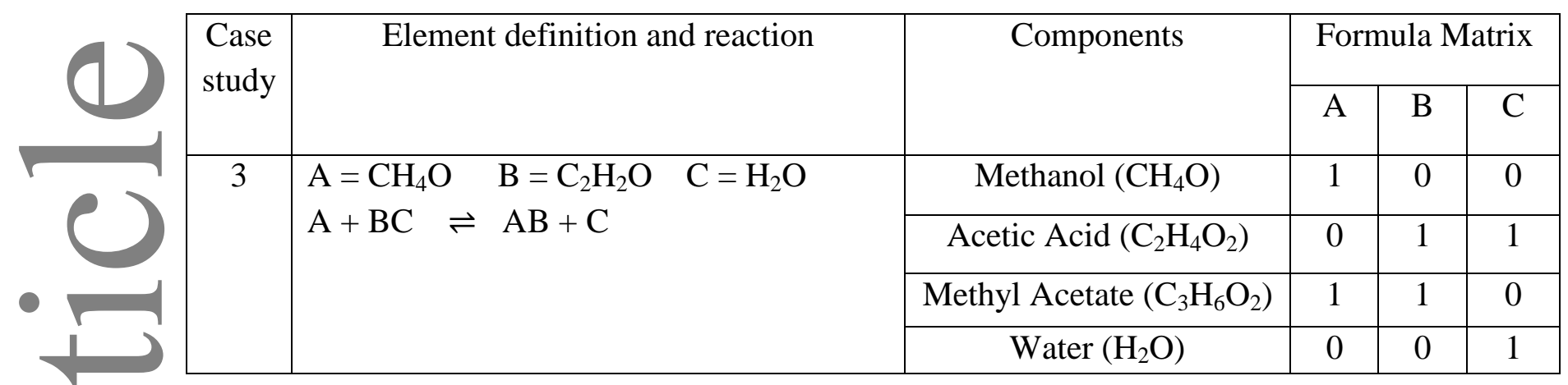


Table 4: Reactive distillation design parameters at the maximum driving force.

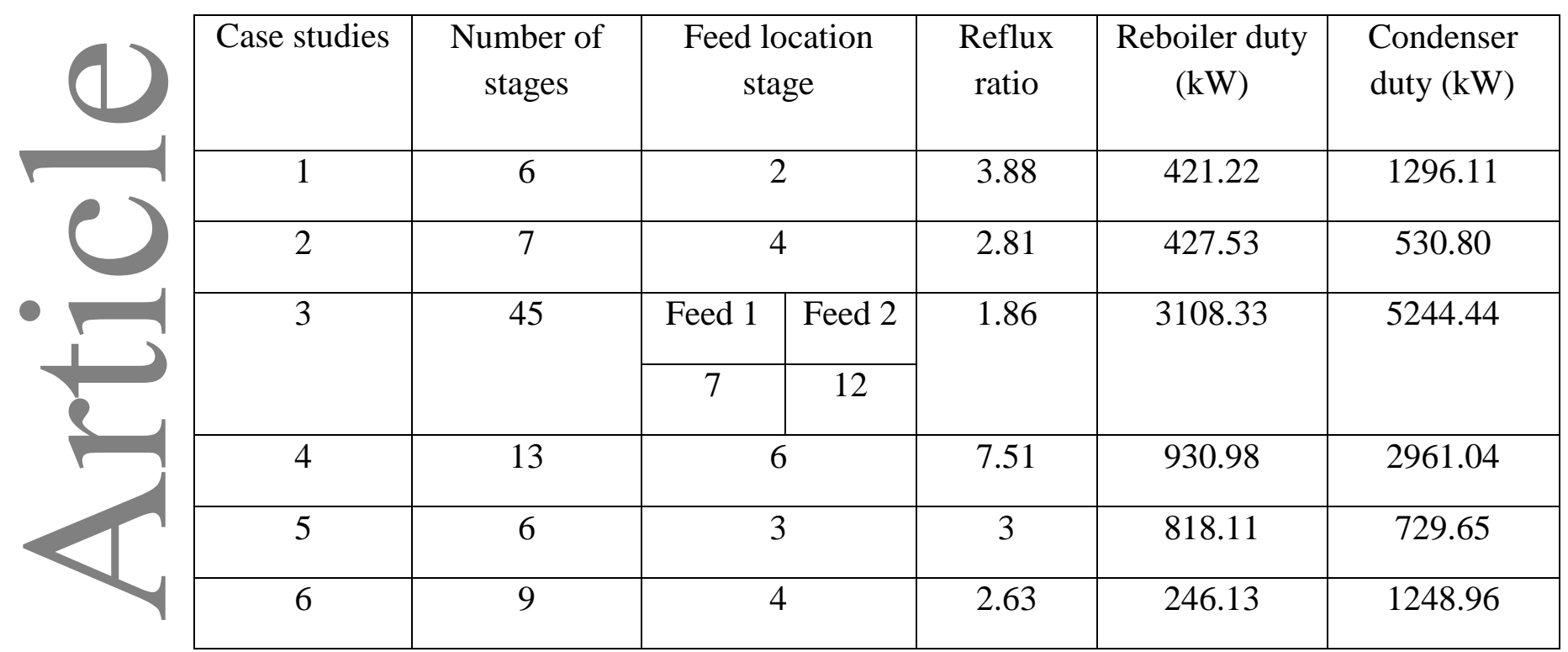


Table 5: RGA, Niederlinski index and system stability for design at the maximum driving force.

\begin{tabular}{|c|c|c|c|c|}
\hline Case studies & $\begin{array}{c}\text { Relative Gain } \\
\text { Array (RGA) }\end{array}$ & $\begin{array}{c}\text { Niederlinski } \\
\text { index }\left(N_{I}\right)\end{array}$ & $\begin{array}{c}\text { Real parts of } \\
\text { all eigenvalues } \\
\text { negative? (both } \\
\text { open loop and } \\
\text { closed loop) }\end{array}$ & Stability \\
\hline 1 & {$\left[\begin{array}{cc}1.26 & -0.26 \\
-0.26 & 1.26\end{array}\right]$} & 0.79 & Yes & Stable \\
\hline 2 & {$\left[\begin{array}{cc}1.26 & -0.26 \\
-0.26 & 1.26\end{array}\right]$} & 0.79 & Yes & Stable \\
\hline 3 & {$\left[\begin{array}{cc}1.09 & -0.09 \\
-0.09 & 1.09\end{array}\right]$} & 0.91 & Yes & Stable \\
\hline 4 & {$\left[\begin{array}{cc}0.85 & 0.15 \\
0.15 & 0.85\end{array}\right]$} & 1.21 & Yes & Stable \\
\hline 5 & {$\left[\begin{array}{cc}0.98 & 0.02 \\
0.02 & 0.98\end{array}\right]$} & 1.03 & Yes & Stable \\
\hline 6 & {$\left[\begin{array}{cc}1.10 & -0.10 \\
-0.10 & 1.10\end{array}\right]$} & 0.77 & Yes & Stable \\
\hline
\end{tabular}


Table 6: Disturbance scenarios

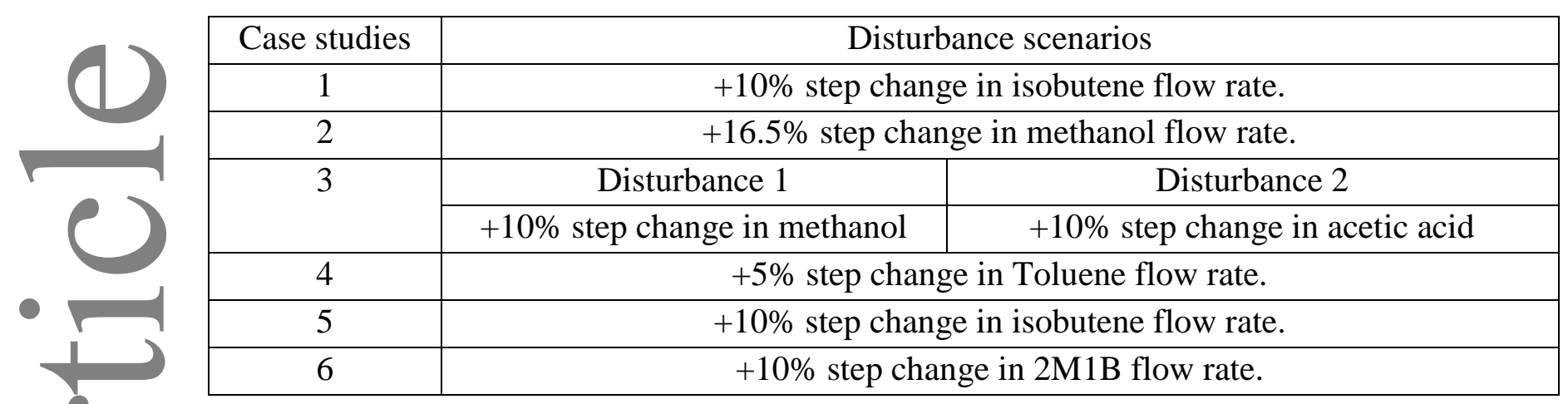

This article is protected by copyright. All rights reserved. 
Table 7: Summary of the performance function terms for the IDC-MDF and the alternative designs for PI and MPC control structure for case study 3.

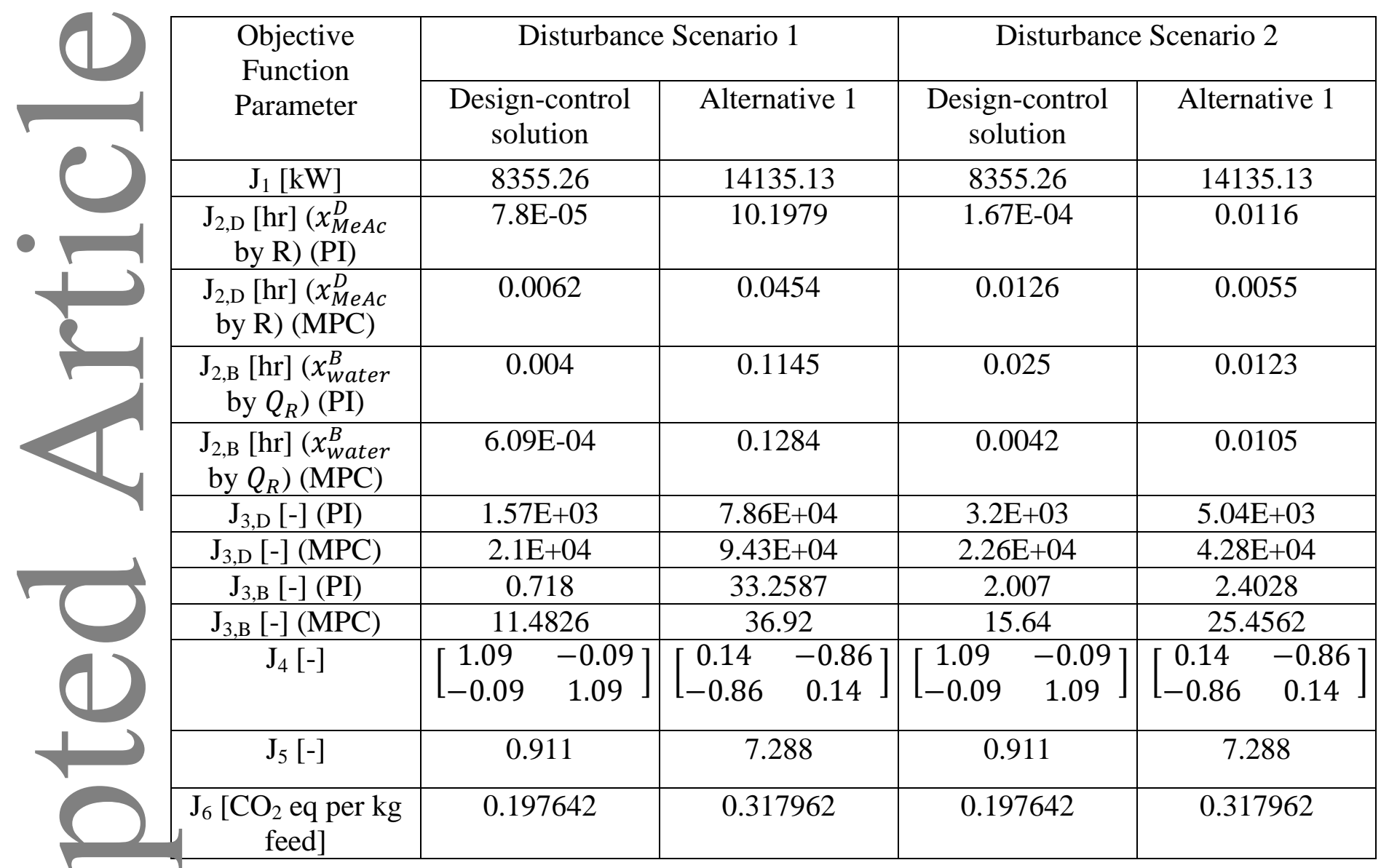

This article is protected by copyright. All rights reserved. 
Table 8: Summary of alternative designs for the six case studies

\begin{tabular}{|c|c|c|c|c|c|c|}
\hline $\begin{array}{c}\text { Case } \\
\text { studies }\end{array}$ & $\begin{array}{l}\text { Number } \\
\text { of stages }\end{array}$ & \multicolumn{2}{|c|}{$\begin{array}{l}\text { Feed } \\
\text { stage }\end{array}$} & $\begin{array}{c}\text { Reflux } \\
\text { ratio }\end{array}$ & $\begin{array}{l}\text { Reboiler } \\
\text { duty }(\mathrm{kW})\end{array}$ & $\begin{array}{l}\text { Condenser } \\
\text { duty }(\mathrm{kW})\end{array}$ \\
\hline 1 & 6 & \multicolumn{2}{|c|}{3} & 5 & 616.69 & 1490.57 \\
\hline 2 & 7 & \multicolumn{2}{|c|}{2} & 7 & 1055.74 & 1162.44 \\
\hline 3 & 45 & 9 & 12 & 6.28 & 6075.34 & 8059.79 \\
\hline 4 & 13 & \multicolumn{2}{|c|}{8} & 9 & 1448.46 & 3478.34 \\
\hline 5 & 6 & \multicolumn{2}{|c|}{4} & 3 & 823.797 & 740.773 \\
\hline 6 & 9 & \multicolumn{2}{|c|}{3} & 3 & 369.664 & 1370.41 \\
\hline
\end{tabular}

This article is protected by copyright. All rights reserved. 


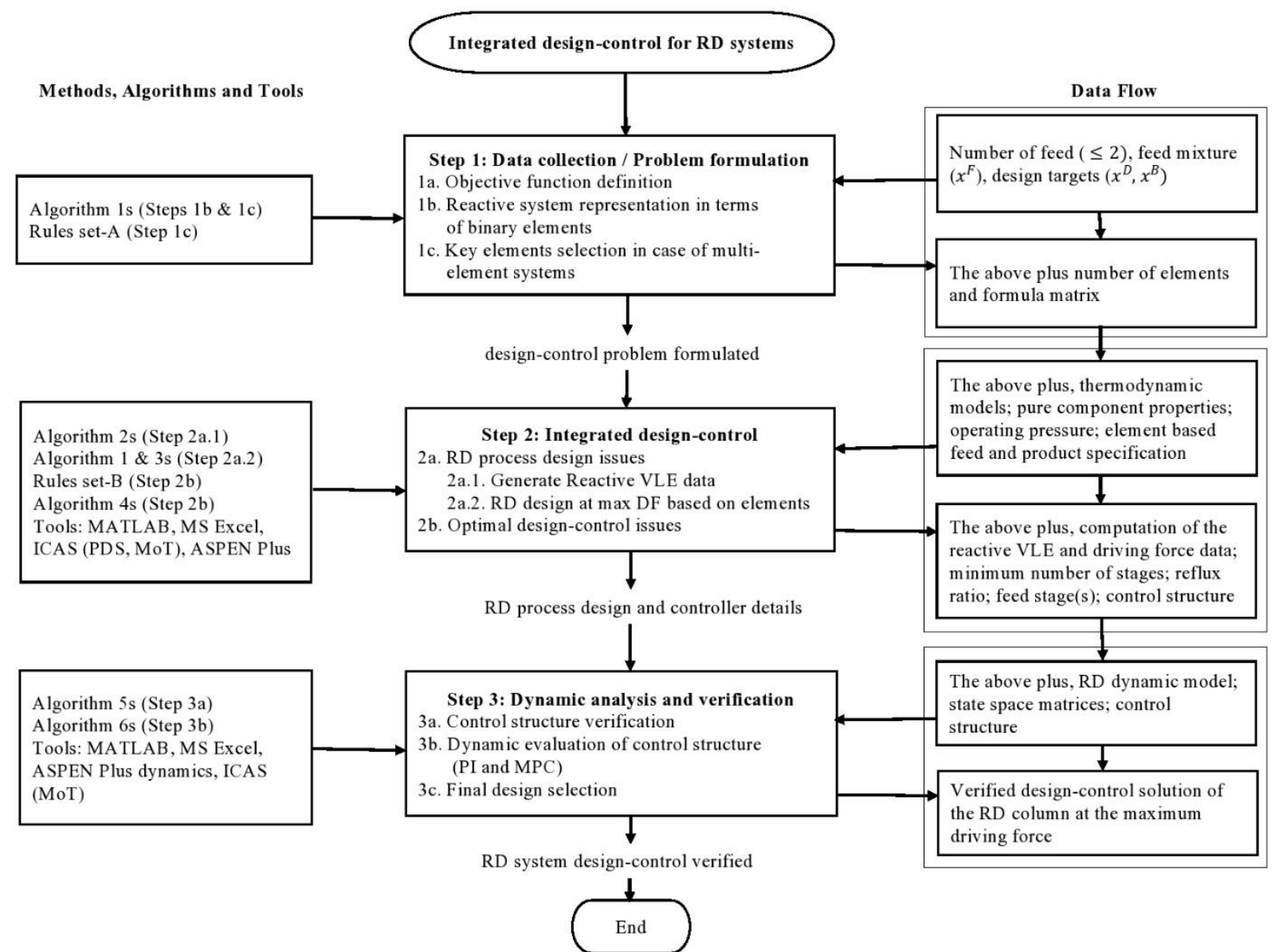

Figure 1: Integrated RD process design-control framework (Algorithm numbers marked with 's' indicates they are included as Supplementary Material). Each box of data-flow indicates data that goes to a step and the generated data that comes from a step; the data stored is cumulative. 


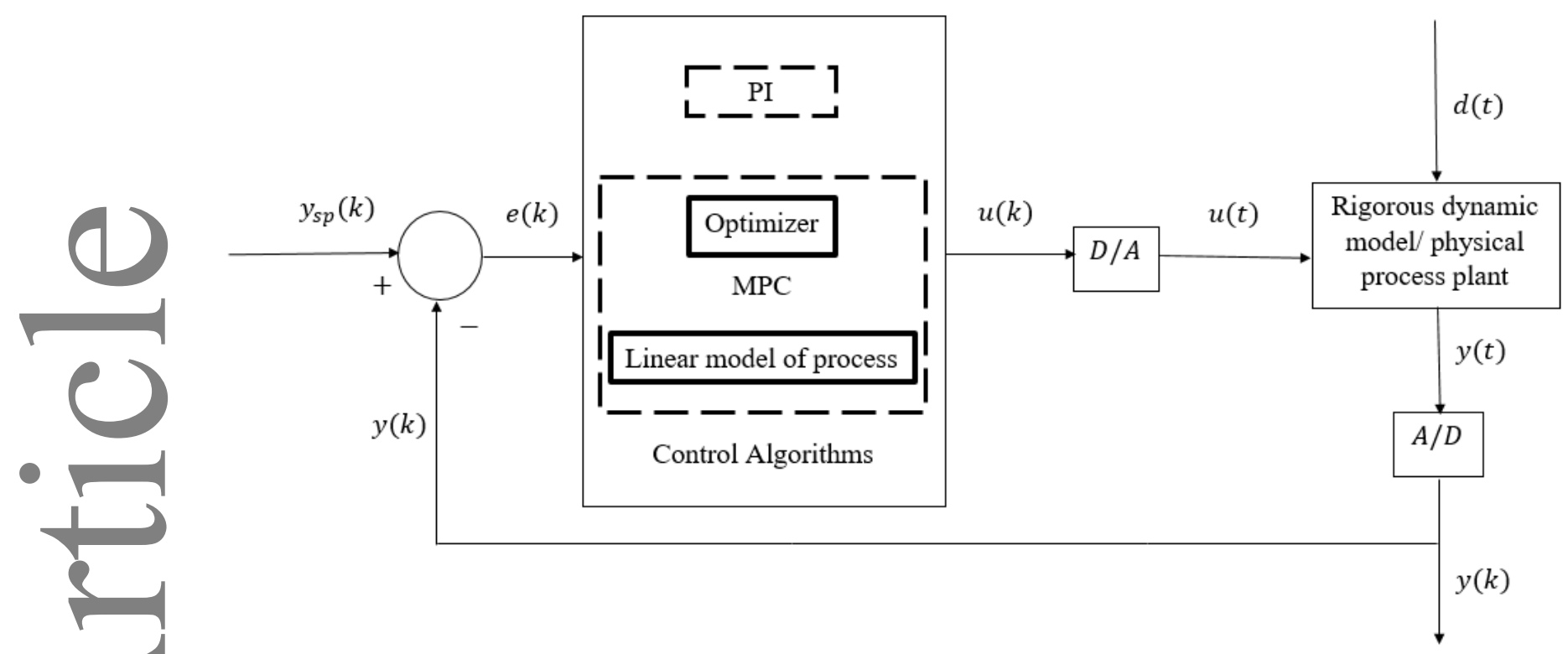

Figure 2: Process-controller block diagram highlighting the PI and MPC controller. 


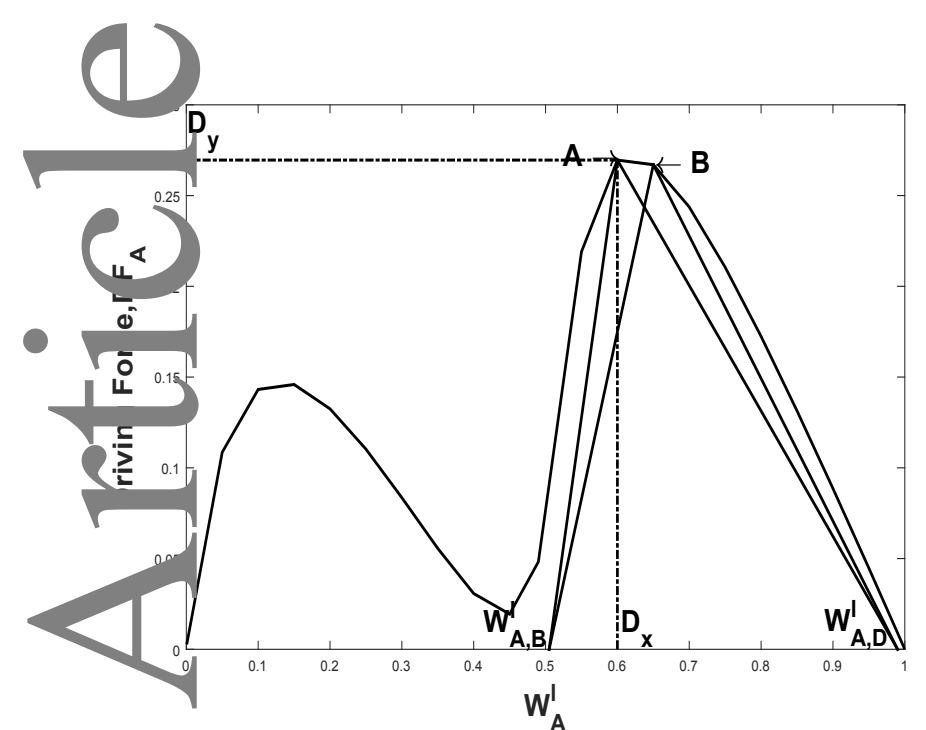

A

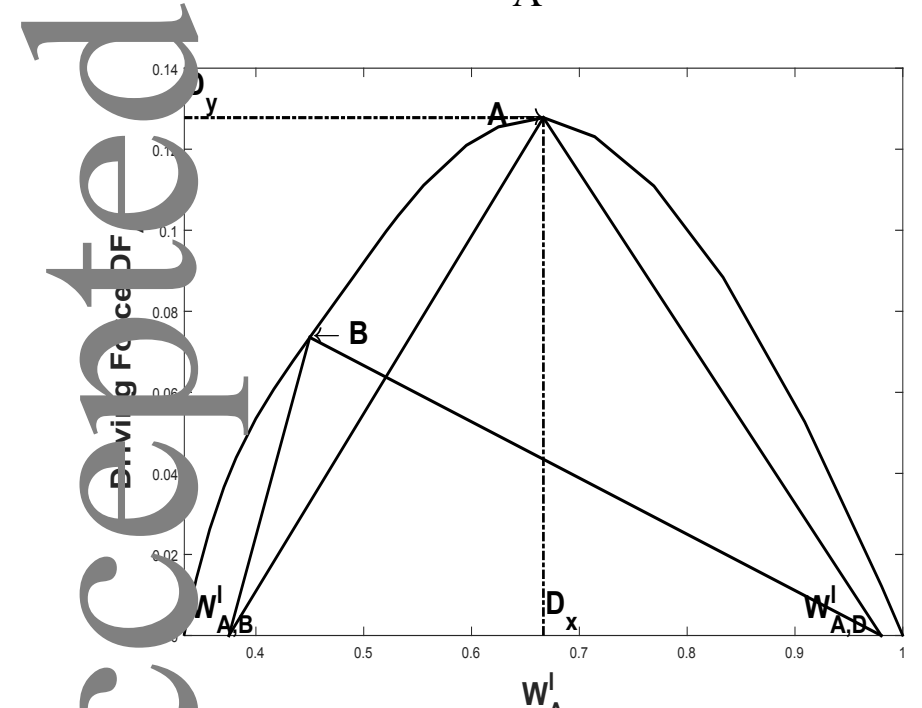

$\mathrm{D}$

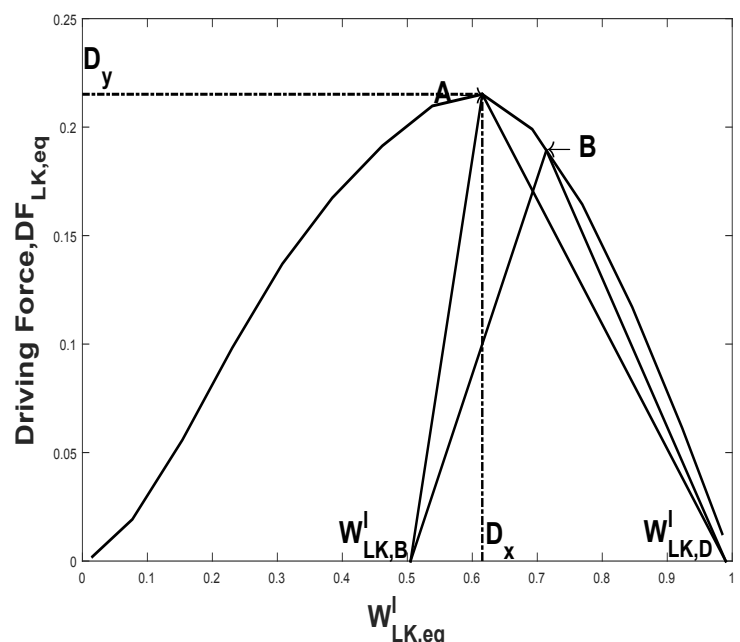

B

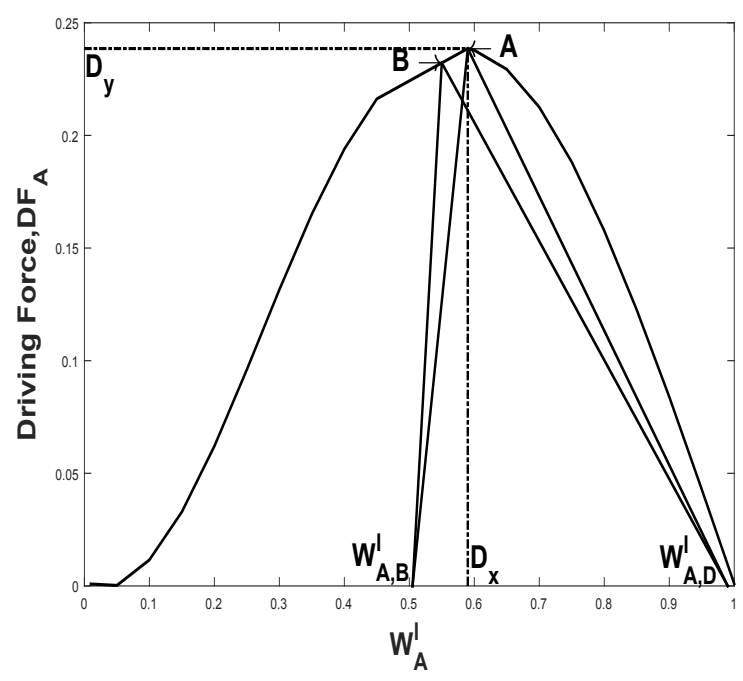

$\mathrm{E}$

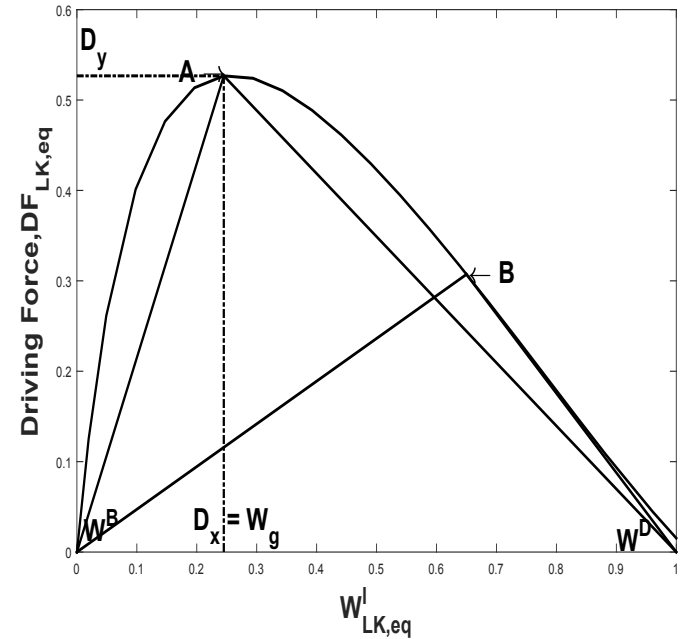

C

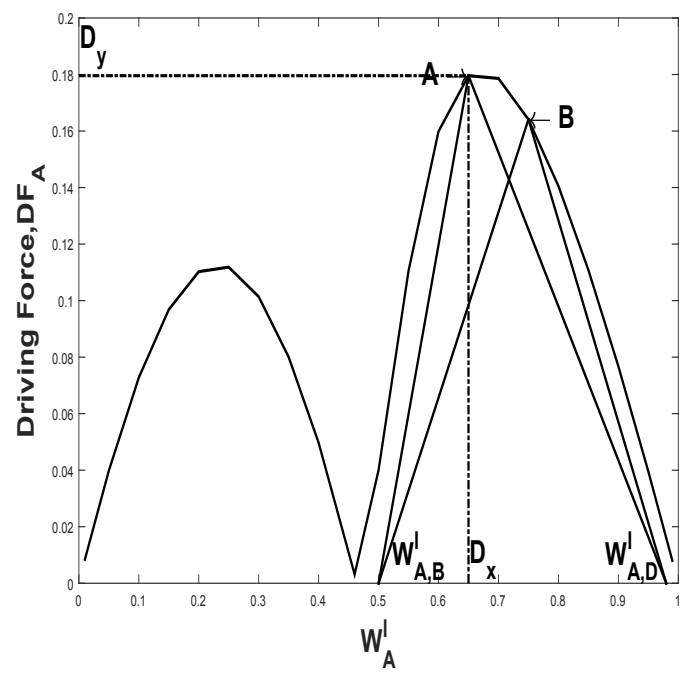

$\mathrm{F}$

Figu 3: Calculated reactive driving force diagram for the 6 reactive systems; A) MTBE without inert (1 atm); B) MTBE with inert (11 atm); C) Methylacetate (1 atm); D) Toluene disproportionation (1 atm); E) ETBE (15 atm); F) TAME (4 bar). 

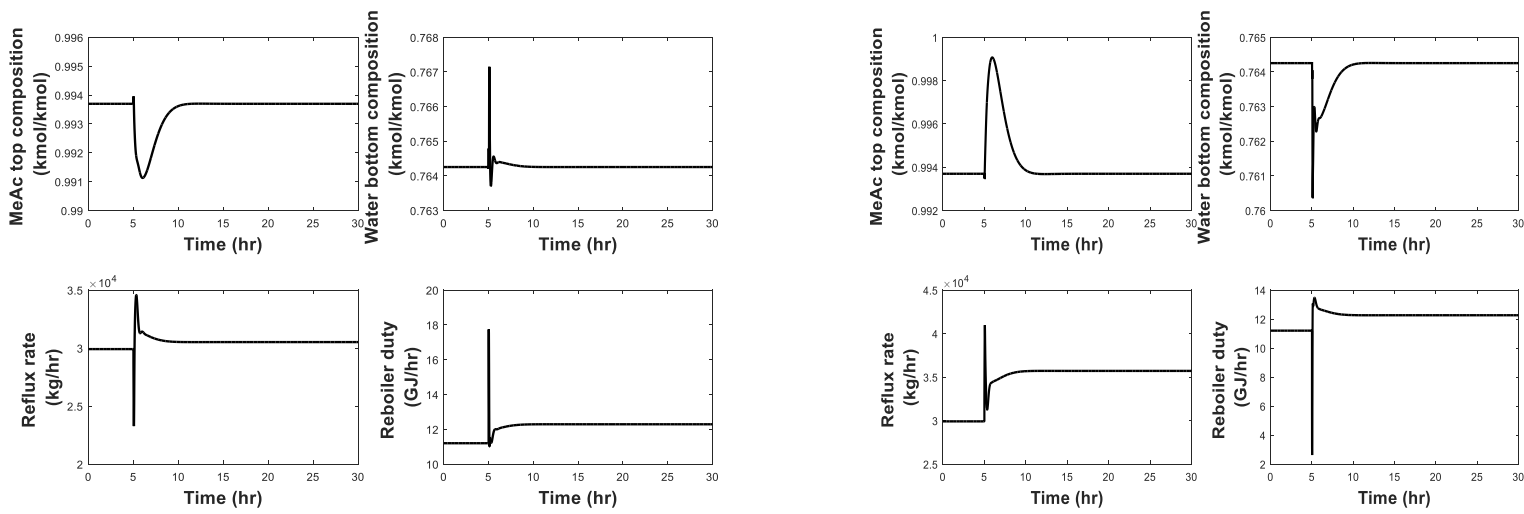

$\mathrm{C}$
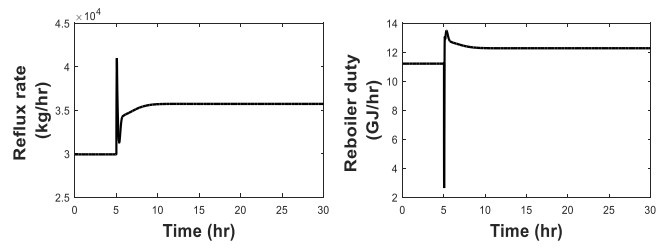

$\mathrm{D}$

Figure 5: Closed-loop response of the IDC-MDF for a step change in the feed flow rate; A) PI controller, $+10 \%$ methanol; B) PI controller, $+10 \%$ acetic acid; C) MPC controller, $+10 \%$ methanol; D) MPC controller, $+10 \%$ acetic acid.
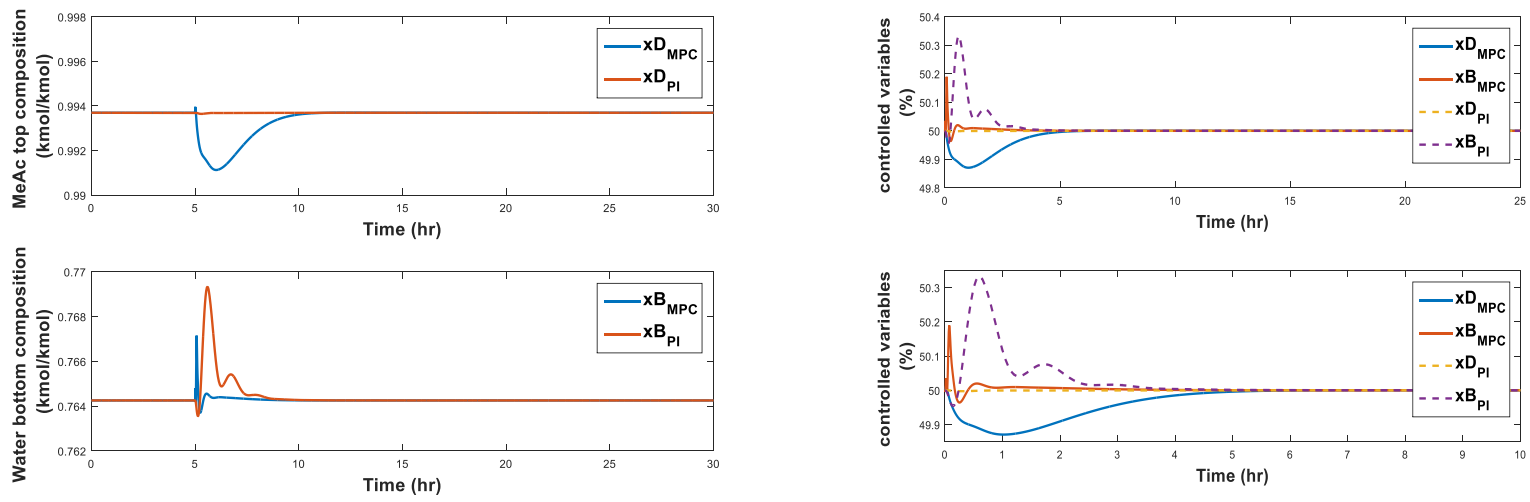

A

B
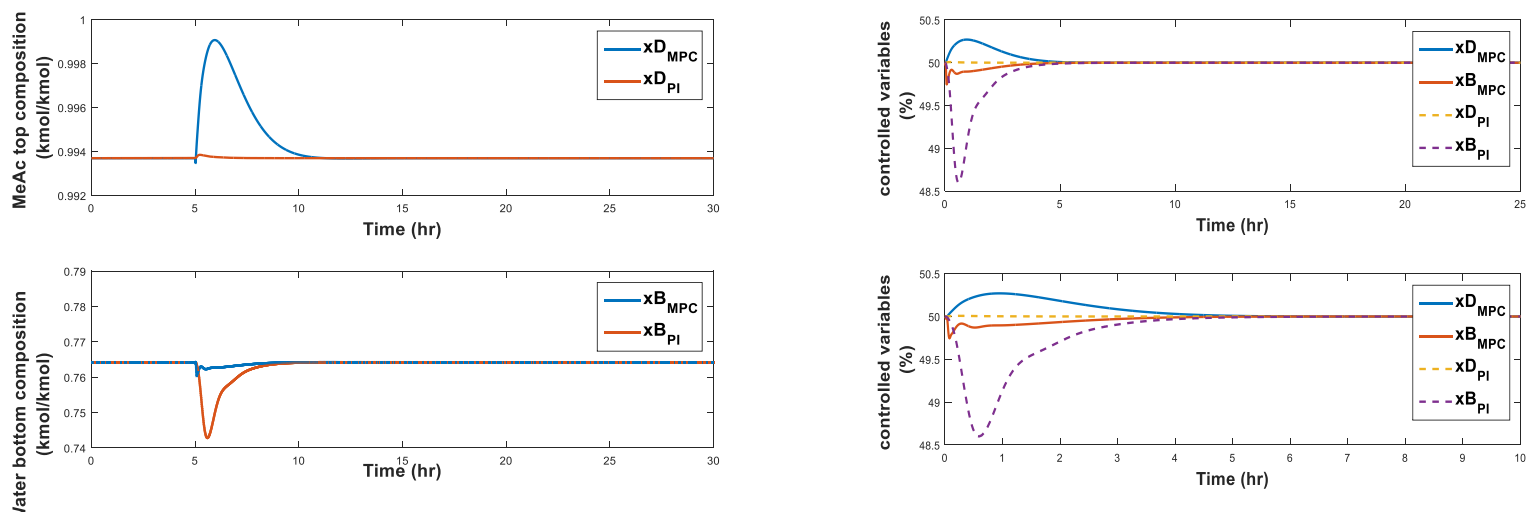

$\mathrm{C}$

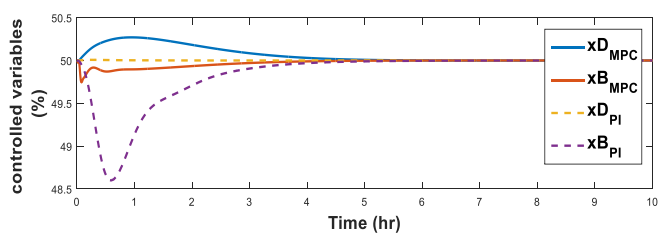

$\mathrm{D}$

Figure 6: Comparison between the controlled outputs under the MPC and PI controllers for IDCMDF; A) $+10 \%$ methanol; composition B) $+10 \%$ methanol; percent deviation; C) $+10 \%$ acetic acid; composition D) $+10 \%$ acetic acid; percent deviation. 

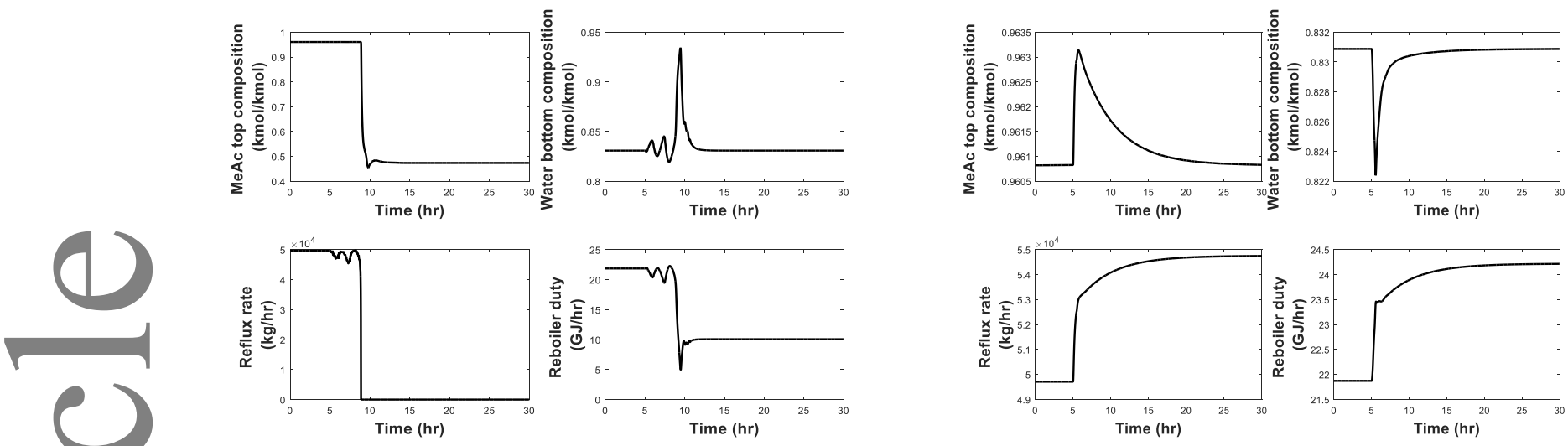

A

$\mathrm{B}$
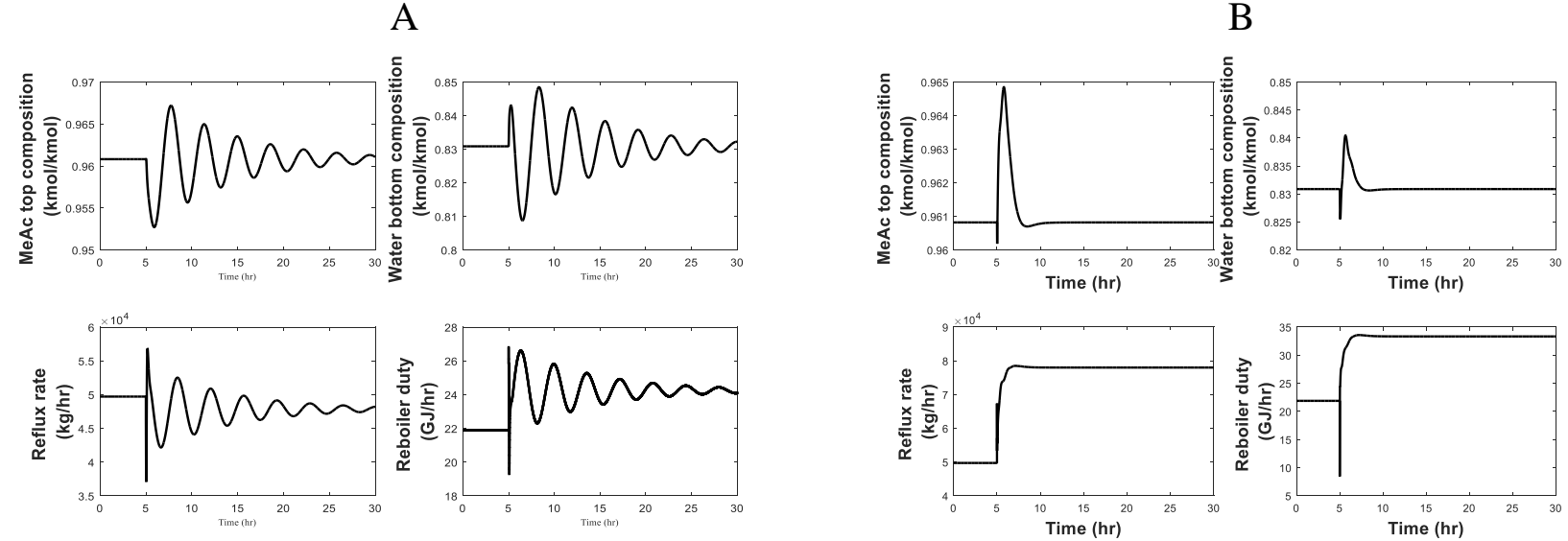

$\mathrm{C}$

$\mathrm{D}$

Figure 7: Closed-loop response of the alternative design for a step change in the feed flow rate; A) PI, $+10 \%$ methanol; B) PI, $+10 \%$ acetic acid; C) MPC,$+10 \%$ methanol; D) MPC, $+10 \%$ acetic acid.
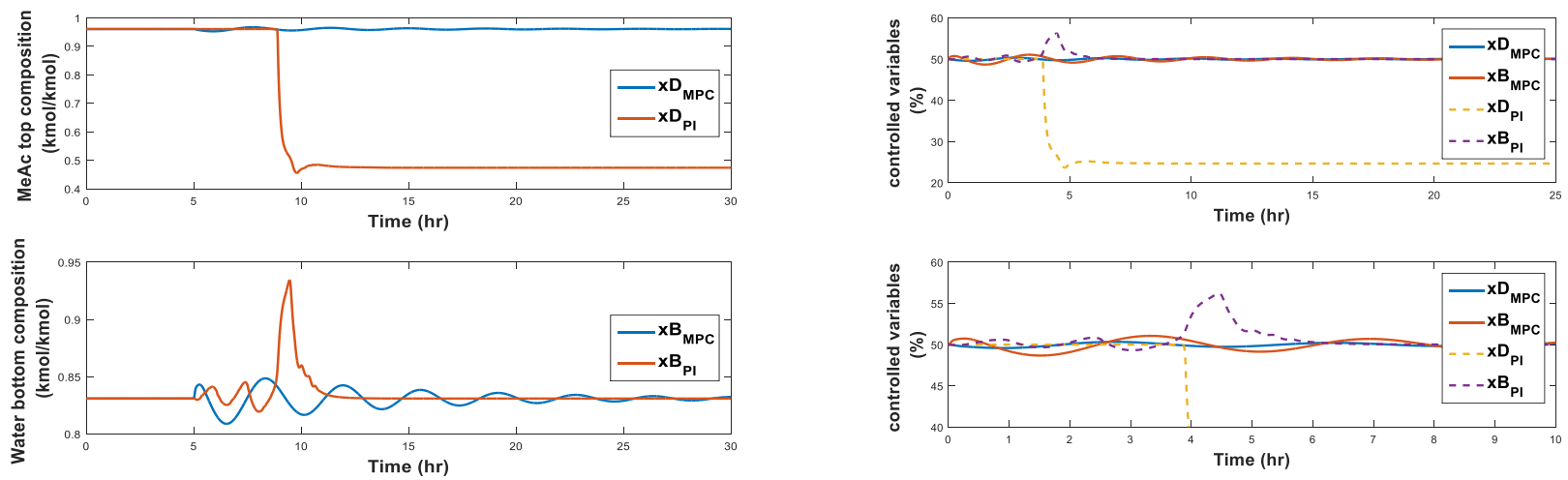

A

B

This article is protected by copyright. All rights reserved. 

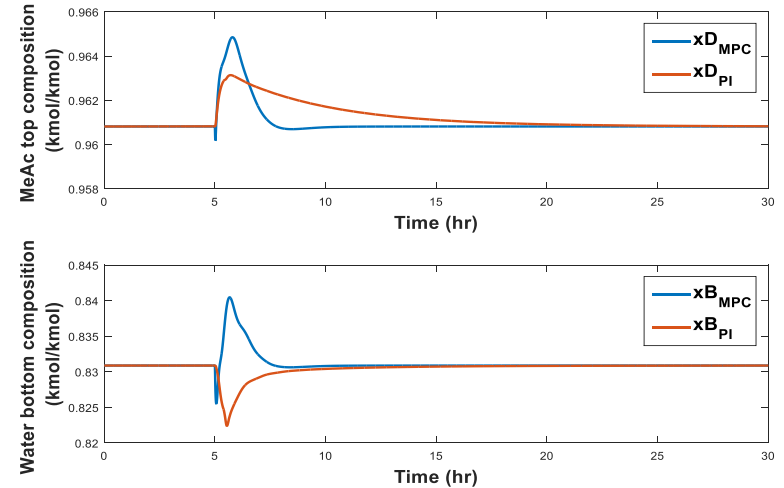

$\mathrm{C}$
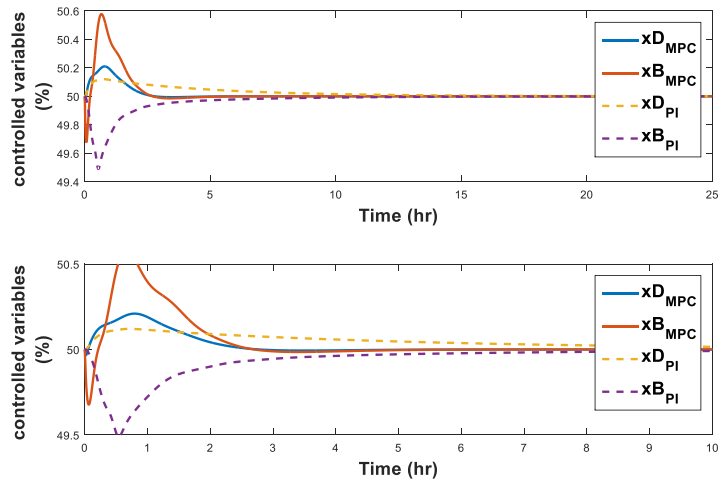

$\mathrm{D}$

Figure 8: Comparison between the controlled outputs under the MPC and PI controllers for the alternative design; A) $+10 \%$ methanol; composition B) $+10 \%$ methanol; percent deviation; C) $+10 \%$ acetic acid; composition D) $+10 \%$ acetic acid; percent deviation. 